\title{
Characterization of Oryza nivara introgression lines: A potential prebreeding resource to improve net photosynthetic rate in elite cultivars of rice
}

\author{
G. HARITHA, T. VISHNUKIRAN, Y. VENKATESWARA RAO, CH. GOWTHAMI, B. DIVYA, \\ N. SARLA, and D. SUBRAHMANYAM ${ }^{+}$
}

Indian Institute of Rice Research (ICAR), Rajendranagar, Hyderabad - 500 030, India

\begin{abstract}
Photosynthesis is one of the fundamental processes influencing crop growth and productivity. In order to understand better the basis of variation in net photosynthetic rate $\left(P_{\mathrm{N}}\right)$ and yield potential in rice, two backcross populations derived from Swarna $\times O$. nivara were studied. Gas exchange and chlorophyll fluorescence measurements were taken at flowering stage and data on yield traits at harvest. $P_{\mathrm{N}}$ was significantly correlated with stomatal conductance, transpiration rate, mesophyll conductance, carboxylation efficiency, yield per plant (YLDP), and dry mass in both populations. Ten introgression lines (ILs) showed higher $P_{\mathrm{N}}$ than their parents. IL 230S showed highest $P_{\mathrm{N}}$ with increased YLDP than the remaining ILs. Single marker analysis showed RM514 and RM48 was positively associated with $P_{\mathrm{N}}$ and YLDP in popA, whereas RM204 and RM122 in popB. The first 4 principal components contributed 92 and $93 \%$ to the total genetic variation in each population, respectively.
\end{abstract}

Additional key words: fluorescence; introgression lines; Oryza nivara; photosynthesis; single marker analysis; yield.

\section{Introduction}

Rice is vital for more than half of the global population and the second most commercially important cereal crop after wheat. Unpredictable climate changes, degradation of natural resources, and a continuous increase of population threaten global food security. Any increase in rice production can be achieved only through increasing grain yield from the limited land resources available. In order to meet this challenge, rice varieties with a higher yield potential have to be developed to minimise the gap between the yield potential and average farm yields. Among many factors associated with the grain yield, photosynthesis is a fundamental physiological process and a key route to increase crop growth rate and genetic yield potential (Masumoto et al. 2004, Long et al. 2015).

Improvement in photosynthesis is important for biomass production. This would help to better utilization of solar radiation which can be translated into the grain yield (Long et al. 2015). Around 90\% of grain dry matter is formed from the products of photosynthesis after heading, particularly from flag leaves (Xie et al. 2011). Further, allocation of photosynthates depends on sourcesink relationships, which in turn are determined by many morpho-physiological traits (Niinemets 2015). However, flag leaf is an important photosynthetic assimilation organ in rice, especially, during the reproductive stage. It plays a greater role in a grain yield increase by contributing about $41-43 \%$ of grain mass (Al-Tahir 2014). In addition, larger flag leaf area during the grain-filling stage also contributes largely to the grain yield by increasing the leaf chlorophyll (Chl) content (Kumari et al. 2011, Al-Tahir 2014).

There is a significant positive association between leaf structural traits and physiological traits (Giuliani et al. 2013). In general, leaf thickness has a positive association with photosynthesis because of a high Chl content in thicker leaves (Rahman et al. 2013) that directly affects the crop biomass (Shen 1980, Chen et al. 1995) and grain

$\overline{\text { Received }} 16$ October 2017, accepted 7 February 2018.

+Corresponding author; phone: +91 40 24591211, fax: +91 40 24591217, e-mail: subbu_desiraj@msn.com

Abbreviations: $C a r$ - carotenoids; $\mathrm{CE}$ - carboxylation efficiency $\left(=P_{\mathrm{N}} / C_{\mathrm{i}}\right) ; C_{\mathrm{i}}-$ intercellular $\mathrm{CO}_{2}$ concentration; $C_{c}-$ chloroplast $\mathrm{CO}_{2}$ concentration; Chl - chlorophyll; TChl - total chlorophyll; DM - dry mass; $E$ - transpiration rate; ETR - electron transport rate; $\mathrm{F}_{\mathrm{v}} / \mathrm{F}_{\mathrm{m}}$ - maximum photochemical efficiency of PSII; $\mathrm{F}_{\mathrm{v}}{ }^{\prime} / \mathrm{F}_{\mathrm{m}}{ }^{\prime}-$ maximum quantum yield of PSII after light adaptation; $g_{\mathrm{m}}-$ mesophyll conductance; $g_{\mathrm{s}}$ - stomatal conductance; $\mathrm{HI}$ - harvest index; $P_{\mathrm{N}}-$ net photosynthetic rate; $\mathrm{q}_{\mathrm{N}}$ - nonphotochemical quenching coefficient; $\mathrm{q}_{\mathrm{P}}-$ photochemical quenching coefficient; $R_{\mathrm{D}}$ - dark respiration; WUE - water-use efficiency $\left(=P_{\mathrm{N}} / E\right)$; WUE - intrinsic water-use efficiency $\left(=P_{\mathrm{N}} / g_{s}\right) ; \Phi_{\mathrm{CO} 2}-$ quantum yield of carboxylation rate; $\Phi_{\mathrm{PSII}}-$ effective quantum yield of PSII photochemistry. YLDP - yield per plant.

Acknowledgements: This work was supported by a grant from the Department of Biotechnology, Government of India, DBT No. BT/ $\mathrm{AB} / \mathrm{FG}$-2(PHII) IA/2009 to NS is gratefully acknowledged. The authors declare no conflict of interest.

\#The authors declare that there are no conflicts of interest. 
yield (Xu and Shen 1994). Unlike stomata, mesophyll is also an important decisive factor in rice photosynthesis as $90 \%$ of chloroplasts are located there. It affects the $\mathrm{CO}_{2}$ diffusion $\left(g_{\mathrm{m}}\right)$ from intercellular air space to carboxylation site and is also influenced by the constitutive properties of leaf anatomy (Giuliani et al. 2013). However, the rate of photosynthesis has been limited by Rubisco carboxylation capacity, which is dependent on the $\mathrm{CO}_{2}$ concentration in chloroplast stroma $\left(C_{\mathrm{c}}\right)(\mathrm{Gu}$ et al. 2012, Giuliani et al. 2013). Since rice is a $C_{3}$ plant, the entire photosynthesis process takes place in mesophyll cells. Therefore, it was expected that the grain yield would be improved by exploitation of morphological and physiological characteristics which are related to gas exchange.

The genetic variability has become very low in modern cultivars due to intense selection for crop yield while ignoring other associated traits, such as photosynthetic rate per unit leaf area (Richards 2000). It is well-known that introgressions from wild species helps improve qualitative traits, such as disease and pest resistance (Kumar et al. 2013, Sarao et al. 2016) as well as quantitative traits, such as the grain yield (Gaikwad et al. 2014, Arbelaez et al. 2015, Ma et al. 2016, Eizenga et al. 2016, 2017, BesshoUehara et al. 2017, Bhatia et al. 2017, Haritha et al. 2018), and abiotic stress tolerance to salinity (Quan et al. 2018), drought (Kaur et al. 2017), and heat (Prasanth et al. 2017) in cultivars. O. rufipogon and $O$. nivara and their derived lines showed a high Chl content, $P_{\mathrm{N}}$, stomatal conductance $\left(g_{\mathrm{s}}\right)$, transpiration rate $(E)$, carboxylation efficiency $(\mathrm{CE})$, and water-use efficiency (WUE) (Zhao et al. 2008, 2010; Kiran et al. 2013, Kondamudi et al. 2016, Haritha et al. 2017, Hamaoka et al. 2017). Total dry mass was improved in $\mathrm{BC}_{2}$ lines derived from $O$. sativa $\times O$. rufipogon (Masumoto et al. 2004, Haritha et al. 2017), whereas, $\mathrm{CE}$ was improved in $\mathrm{BC}_{2} \mathrm{~F}_{2}$ lines derived from new plant type $(\mathrm{NPT})$ rice line IR65598-110-2 $\times$ O. longistaminata (Ding et al. 2014) compared to parents. Therefore, wild species could be utilized as a potential source for further improvement in leaf structural and physiological traits which ultimately improve the resource-use efficiency in modern cultivars.

The objective of this study was to investigate the variation in leaf photosynthetic efficiency and related traits in back-cross introgression lines $\left(\mathrm{BC}_{2} \mathrm{~F}_{6}-\mathrm{BILs}\right)$ derived from the wild rice species $O$. nivara and a lowland cultivated indica rice variety Swarna. Further, we wanted to examine whether photosynthetic efficiency of Swarna can be improved by the introgressions from $O$. nivara and to provide an insight into how the variation in photosynthetic efficiency is related to improvements in biomass production and grain yield. In addition, we aimed to investigate the marker-trait association for leaf gas exchange and yield traits using SSR markers to determine any common associated loci which influence the photosynthetic efficiency and grain yield.

\section{Materials and methods}

Plant material: The experiment was conducted in green house at Indian Institute of Rice Research (IIRR),
Hyderabad (17\% 32' N, 78 40' E) during dry season 2013 (November 2013 - June 2014) under well-watered conditions. A total of 52 BILs were selected based on their grain yield from two $\mathrm{BC}_{2} \mathrm{~F}_{6}$ populations developed using a common recurrent parent Swarna and two wild accessions of $O$. nivara as donor parents. A population A consisted of 27 BILs derived from Swarna $\times$ O. nivara IRGC81848, and the population B consisted of 25 BILs derived from Swarna $\times$ O. nivara IRGC81832. Hereafter, the population $\mathrm{A}$ and population $\mathrm{B}$ are referred as popA and popB, respectively. Ten-days-old seedlings were transferred to clay pots $(26 \times 30 \mathrm{~cm}$, volume of $15 \mathrm{~L})$ at a density of three plants per pot filled with loam soil. Each introgression line (IL) was grown with a recommended fertilizer dose in three replicated pots.

The weather parameters recorded during the crop growth period were shown in Fig. 1S (supplement). The mean maximum temperature recorded during the crop growth period was $32.6^{\circ} \mathrm{C}$, while the mean minimum temperature was $15.9^{\circ} \mathrm{C}$ and average relative humidity was $79.5 \%$. The mean sunshine duration was $8.3 \mathrm{~h}$ per day and mean solar radiation levels was $18.3 \mathrm{~W} \mathrm{~m}^{-2}$. The temperature and RH were recorded using a datalogger (model DT-172, CEM Instruments, India) installed inside the greenhouse, whereas data on solar radiation and duration of sunshine were obtained from the automatic weather station (Campbell Scientific, USA) installed at IIRR farm.

Gas-exchange and leaf fluorescence measurements: These determinants were measured simultaneously on three fully-expanded flag leaves $3 \mathrm{~d}$ after anthesis from each replication, using a portable open gas-exchange system (LI6400XT, LI-COR, Lincoln, NE, USA) with an integrated fluorescence chamber head (LI 6400-40, LI-COR, USA) which is used as a light source. Respiration rate $\left(R_{\mathrm{D}}\right)$ of the flag leaf was measured by covering the leaf chamber with black cloth in the early hours (05:00 06:00 h) and this parameter was used for calculating mesophyll conductance $\left(g_{\mathrm{m}}\right)$. Leaf gas-exchange and fluorescence traits were measured between 09:00-12:00 h on clear days with PPFD at $1,000 \mu \mathrm{mol} \mathrm{m} \mathrm{m}^{-2} \mathrm{~s}^{-1}$. During measurements the leaf chamber air temperature was set at $30^{\circ} \mathrm{C}$. The gas-exchange traits, such as $P_{\mathrm{N}}, g_{\mathrm{s}}, E$, and $C_{\mathrm{i}}$ were measured at ambient $\mathrm{CO}_{2}$ concentration at $400 \mu \mathrm{mol}$ $\mathrm{mol}^{-1}$. Water-use efficiency (WUE), intrinsic water-use efficiency $\left(W_{U} E_{i}\right)$, and carboxylation efficiency $(\mathrm{CE})$ were calculated based on the ratios of $P_{\mathrm{N}}$ to $E, g_{\mathrm{s}}$, and $C_{\mathrm{i}}$ values, respectively.

Similarly leaf Chl fluorescence parameters were calculated according to Björkman and Demmig (1987): maximum quantum efficiency of PSII $\left[\mathrm{F}_{\mathrm{v}} / \mathrm{F}_{\mathrm{m}}=\left(\mathrm{F}_{\mathrm{m}}-\mathrm{F}_{0}\right) / \mathrm{F}_{\mathrm{m}}\right]$, maximum quantum yield of PSII after light adaptation $\left[\mathrm{F}_{\mathrm{v}}{ }^{\prime} / \mathrm{F}_{\mathrm{m}}{ }^{\prime}=\left(\mathrm{F}_{\mathrm{m}}{ }^{\prime}-\mathrm{F}_{0}{ }^{\prime}\right) / \mathrm{F}_{\mathrm{m}}{ }^{\prime}\right]$, photochemical quenching coefficient $\left[\mathrm{q}_{\mathrm{P}}=\left(\mathrm{F}_{\mathrm{m}}{ }^{\prime}-\mathrm{F}_{\mathrm{s}}{ }^{\prime}\right) /\left(\mathrm{F}_{\mathrm{m}}{ }^{\prime}-\mathrm{F}_{0}{ }^{\prime}\right)\right]$, nonphotochemical quenching coefficient $\left[\mathrm{q}_{\mathrm{N}}=\left(\mathrm{F}_{\mathrm{m}}-\mathrm{F}_{\mathrm{m}}{ }^{\prime}\right) / \mathrm{F}_{\mathrm{m}}{ }^{\prime}\right]$, effective quantum yield of PSII photochemistry $\left[\Phi_{\text {PSII }}=\left(\mathrm{F}_{\mathrm{m}}{ }^{\prime}-\mathrm{F}_{\mathrm{s}}\right) / \mathrm{F}_{\mathrm{m}}{ }^{\prime}\right]$ (Genty et al. 1989) and quantum yield of carboxylation rate $\left(\Phi_{\mathrm{CO} 2}\right)$. Finally, the apparent photosynthetic electron transportation rate through PSII (ETR) was calculated 
$\left[\mathrm{ETR}=\Phi_{\mathrm{PSII}} \times 0.84 \times \mathrm{PPFD} \times 0.5\right]$, where $\mathrm{PPFD}$ is photosynthetic photon flux density of absorbed light in $\mu$ mol(photon) $\mathrm{m}^{-2} \mathrm{~s}^{-1}$ considering 0.84 or $84 \%$ light intensity and 0.5 is a factor which accounts for the partitioning of energy between PSII and PSI (Maxwell and Johnson 2000).

Estimation of mesophyll conductance in BILs: Mesophyll conductance $\left(g_{\mathrm{m}}\right)$ was measured following the 'variable J' method of Harley et al. (1992):

$g_{\mathrm{m}}=P_{\mathrm{N}} /\left(C_{\mathrm{i}}-\left\{\Gamma^{*}\left[\mathrm{ETR}+8\left(P_{\mathrm{N}}+R_{\mathrm{D}}\right)\right] /\left[\mathrm{ETR}-4\left(P_{\mathrm{N}}+R_{\mathrm{D}}\right)\right]\right\}\right)$

where $P_{\mathrm{N}}$ is net photosynthetic rate and $C_{\mathrm{i}}$ is internal $\mathrm{CO}_{2}$ concentration. These were obtained from gas-exchange measurements. $R_{\mathrm{D}}$ is respiration rate which was measured during the morning hours (05:00-06:00 h). Before the measurement, all plants were covered with black cloth and $R_{\mathrm{D}}$ was measured in dark. $\Gamma^{*}$ is the $\mathrm{CO}_{2}$-compensation point and the value is adapted from the report of Sexton et al. (2013). Now, $C_{\mathrm{c}}$ is the chloroplast $\mathrm{CO}_{2}$ concentration calculated from the following equation of Adachi et al. (2013): $C_{\mathrm{c}}=C_{\mathrm{i}}-P_{\mathrm{N}} / g_{\mathrm{m}}$

Leaf Chl and carotenoid (Car) contents: The flag leaves used for the leaf gas-exchange and fluorescence measurements were detached from the plants. Briefly, $0.1 \mathrm{~g}$ of leaf tissue was inserted in 50-ml volumetric flask, which contained $25 \mathrm{ml}$ of $80 \%$ acetone (v/v) (Merck, India). In order to avoid a light exposure, the flasks were wrapped with aluminium foil and kept in dark at room temperature for $48 \mathrm{~h}$. An aliquot ( $1 \mathrm{ml}$ ) of extract was used for measurements of absorbance at $663(\mathrm{Chl} a), 645$ (Chl b), and $470 \mathrm{~nm}$ (Car) using a spectrophotometer (Spectrascan UV 2600, Toshniwal Instruments, India). The amounts of $\mathrm{Chl}$ and Car were calculated according to the method of Lichtenthaler and Wellburn (1983). The concentration of Chl was expressed as $\mathrm{mg} \mathrm{g}^{-1}$ (leaf fresh mass, FM).

Phenotyping of yield and other related traits: The BILs and their parents were harvested at a final maturity stage from each replication to determine the yield and related traits, such as plant height $(\mathrm{PH})$, a number of tillers per plant (NT), number of panicles per plant (NP), panicle length (PL), number of primary branches (PB), number of secondary branches (SB), total number of grains per panicle (TNG), spikelet fertility (SPF), panicle mass (PW), thousand-grain mass (TGW), yield per plant (YLDP), dry mass (DM), and harvest index (HI).

Genotyping: Genomic DNA of parents Swarna, O. nivara, and 52 BILs was extracted from young leaves using CTAB (cetyl trimethyl ammonium bromide) method (Rogers and Bendich 1988) and screened using 73 SSR markers which were polymorphic between Swarna and $O$. nivara. The PCR amplification was carried out in $10-\mu 1$ reaction volume containing $50 \mathrm{ng}$ of template DNA, $0.2 \mu \mathrm{M}$ of each primer (both forward and reverse primers) and Emerald Amp PCR Master Mix (Takara Bio, USA). The PCR amplification was performed using a programmable thermal cycler (Applied Biosystems Veriti, Thermo Fischer
Scientifics, California, USA) under the following conditions: initial denaturation at $94^{\circ} \mathrm{C}$ for $5 \mathrm{~min}$, followed by 35 cycles of denaturation at $94^{\circ} \mathrm{C}$ for $30 \mathrm{~s}$, annealing at $55^{\circ} \mathrm{C}$ for $30 \mathrm{~s}$, extension at $72^{\circ} \mathrm{C}$ for $1 \mathrm{~min}$, followed by the final extension at $72^{\circ} \mathrm{C}$ for $7 \mathrm{~min}$. Following amplification, the products were checked for marker segregation in $3 \%$ agarose gel.

Linkage map construction and single marker analysis: Linkage maps were constructed from the genotyping data of 73 polymorphic markers in both populations separately using the Mapmaker version 3.0 (Lander and Botstein 1989, Lincoln et al. 1993) following Kosambi function (Kosambi 1944). Single marker analysis (SMA) was performed to determine the association between marker and trait using QTL cartographer ver. 2.5 (Wang et al. 2011).

Statistical analysis: Significant differences were determined by analysis of variance $(A N O V A)$ and means were compared by Tukey's HSD test $(p<0.05)$ for all traits using an open source software $R$ ( $R$ Core Team 2012) with Agricolae package (de Mendiburu 2012). Multiple correlations were performed between gas exchange and yield related traits using Microsoft Excel 2007. Principal component analysis (PCA) was performed based on the covariance matrix to identify the percent contribution of each trait to the total genetic variation in the introgression lines of both populations using statistical analysis for agricultural research STAR ver. 2.0.1 (IRRI 2013).

\section{Results}

Comparative analysis of net photosynthetic rate and other gas-exchange traits: Significant differences were found in $P_{\mathrm{N}}$ between the backcross-introgression lines (BILs) compared to their parents, Swarna and $O$. nivara. $P_{\mathrm{N}}$ ranged from 10.4-23.1 and 9.0-21.5 $\mu \mathrm{mol}\left(\mathrm{CO}_{2}\right) \mathrm{m}^{-2} \mathrm{~s}^{-1}$ in popA and popB, respectively. There were 20 BILs in popA and 12 BILs in popB showing higher $P_{\mathrm{N}}$ than that of Swarna. Of these, 4 BILs (230S, 75S, 214S, and 33S) from popA and 6 BILs $(173 \mathrm{~K}, 3-1 \mathrm{~K}, 24 \mathrm{~K}, 45 \mathrm{~K}, 75 \mathrm{~K}$, and $131 \mathrm{~K})$ from popB showed higher $P_{\mathrm{N}}$ than their respective donor wild accession. The variation among BILs was significant for $g_{\mathrm{s}}$ in both populations. It ranged from $0.16-0.83$ and $0.19-0.65 \mathrm{~mol}\left(\mathrm{H}_{2} \mathrm{O}\right) \mathrm{m}^{-2} \mathrm{~s}^{-1}$ in popA and popB, respectively. In all, 9 BILs showed higher $P_{\mathrm{N}}$ and $g_{\mathrm{s}}$ than that of their parents. Leaf transpiration rate $(E)$ showed significant differences between the BILs. These differences varied from 3.9-11.2 and 4.8-11.1 mmol $\left(\mathrm{H}_{2} \mathrm{O}\right) \mathrm{m}^{-2} \mathrm{~s}^{-1}$ in popA and popB, respectively (Fig. 1). Three BILs from each population showed higher $E$ than parents. Similarly, a wide variation was observed in $C_{\mathrm{i}}$ which ranged between 228.5-343.5 and 234.1-341.3 $\mu \mathrm{mol}\left(\mathrm{CO}_{2}\right) \mathrm{mol}^{-1}$ in popA and in popB, respectively.

The variations observed in WUE and CE were significant in both populations. WUE was the highest in IL 26S $\left[3.06 \mu \mathrm{mol}\left(\mathrm{CO}_{2}\right) \mathrm{mmol}^{-1}\left(\mathrm{H}_{2} \mathrm{O}\right)\right]$ in popA and the lowest one in Swarna $\left[1.44 \mu \mathrm{mol}\left(\mathrm{CO}_{2}\right) \mathrm{mmol}^{-1}\left(\mathrm{H}_{2} \mathrm{O}\right)\right]$. In popB, it ranged from 1.12 (IL $138 \mathrm{~K}$ ) to 2.62 (IL $45 \mathrm{~K}) \mu \mathrm{mol}\left(\mathrm{CO}_{2}\right)$ $\mathrm{mmol}^{-1}\left(\mathrm{H}_{2} \mathrm{O}\right)$. However, $\mathrm{CE}$ was maximum in IL $148 \mathrm{~S}$ 


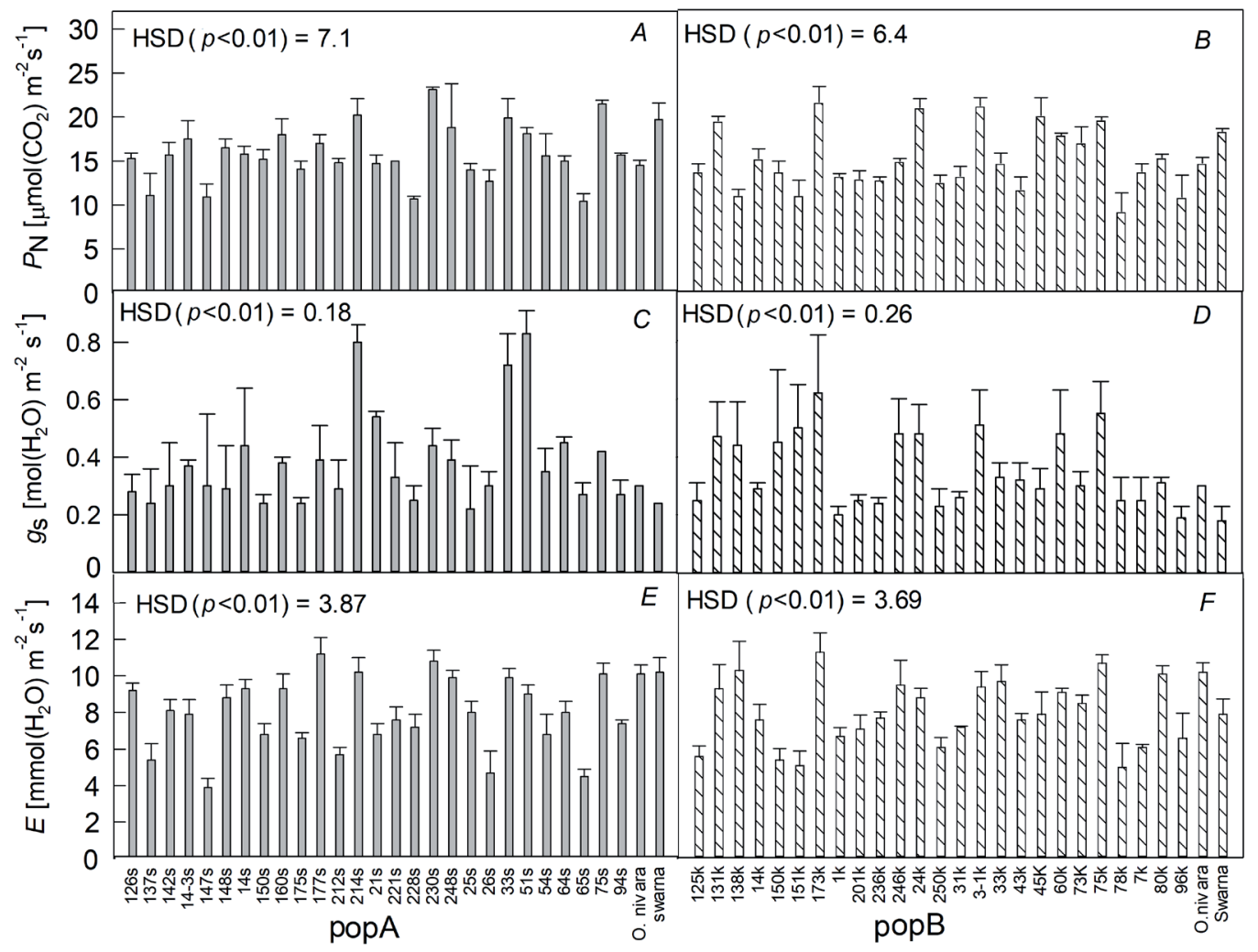

Fig. 1. Variation in net photosynthetic rate $\left(P_{\mathrm{N}}\right)(A, B)$, stomatal conductance $\left(g_{\mathrm{s}}\right)(C, D)$, and transpiration rate $(E)(E, F)$ in two $\mathrm{BC}_{2} \mathrm{~F}_{6}$ populations, popA (Swarna $\times$ O. nivara IRGC818) and popB (Swarna $\times$ O. nivara IRGC81832). Each bar represent the mean of three replications $\pm \mathrm{SD}$.

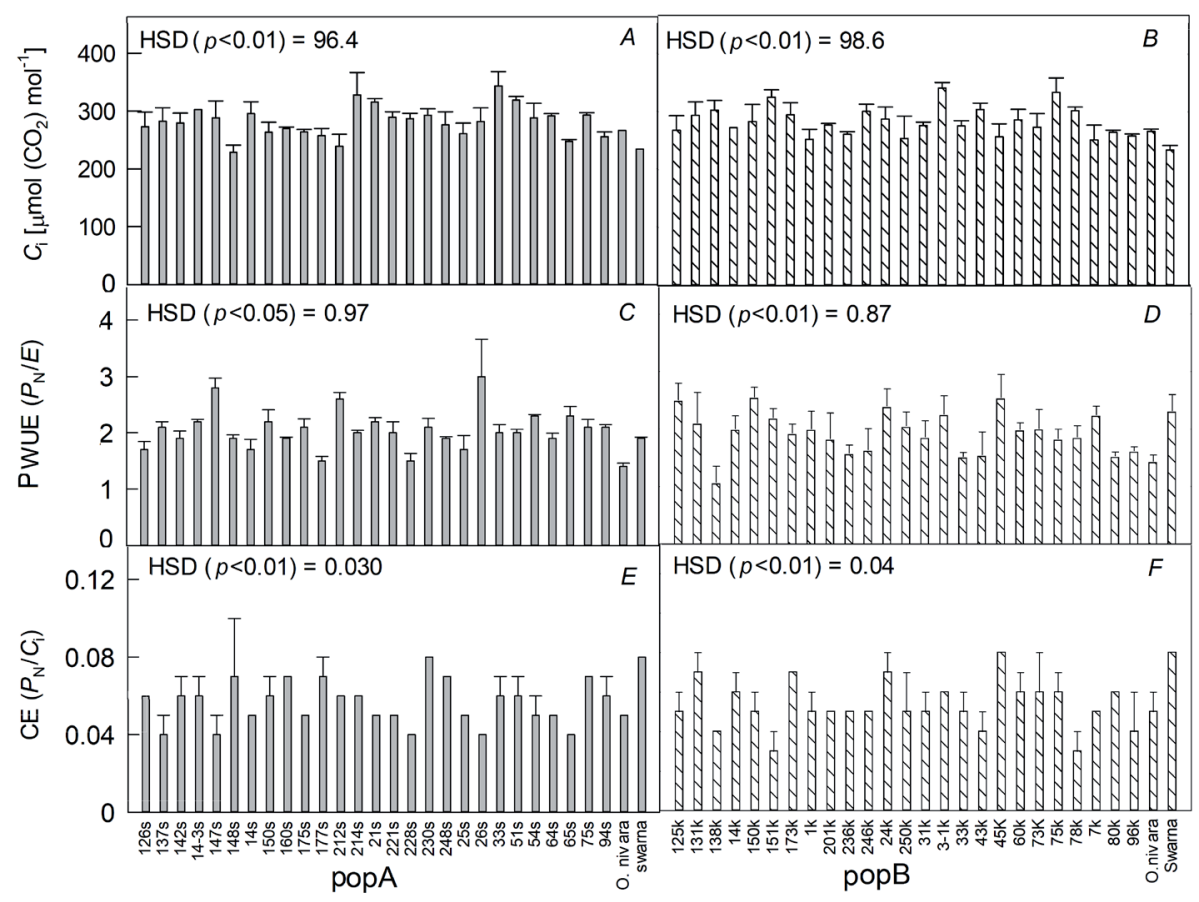

Fig. 2. Variation in intercellular $\mathrm{CO}_{2}$ concentration $\left(C_{\mathrm{i}}\right)(A, B)$, photosynthetic water-use efficiency (WUE) $(C, D)$, and carboxylation efficiency $(\mathrm{CE})(E, F)$ in two $\mathrm{BC}_{2} \mathrm{~F}_{6}$ populations, popA (Swarna $\times$ O. nivara IRGC818) and popB (Swarna $\times$ O. nivara $\mathrm{IRGC81832)}$. Each bar represent the mean of three replications $\pm \mathrm{SD}$. 
$\left[0.085 \mu \mathrm{mol}\left(\mathrm{CO}_{2}\right) \mathrm{mol}^{-1}\right.$ (air)] and minimum in IL $228 \mathrm{~S}$ $\left[0.037 \mu \mathrm{mol}\left(\mathrm{CO}_{2}\right) \mathrm{mol}^{-1}\right]$, whereas in popB it ranged from 0.078 (O. nivara) to 0.030 (IL 78K) $\mu \mathrm{mol}\left(\mathrm{CO}_{2}\right) \mathrm{mol}^{-1}$ (air) (Fig. 2).

Chl fluorescence: $F_{v} / F_{m}$ was found to be almost identical in both populations and showed no significant variations among the BILs. It ranged between both the parents and was the highest in O. nivara (0.77) and the lowest in Swarna $(0.68)$ in both populations. Similarly, $F_{v}{ }^{\prime} / F_{m}{ }^{\prime}$ showed significant differences ranging from $0.45-0.63$ in popA, but differences were not significant in popB. Furthermore, ETR also showed significant variations in both populations. It was the highest in IL 75S (143.8) and IL $60 \mathrm{~K}$ (135.6), and the lowest in $O$. nivara parents of both populations (Fig. 3). The variation observed for $\Phi_{\mathrm{PSII}}$ and $\Phi_{\mathrm{CO} 2}$ were significant (Fig. 4). Similarly, $\mathrm{q}_{\mathrm{P}}$ and $\mathrm{q}_{\mathrm{N}}$ also showed wide variations among the BILs. Swarna showed significantly higher $\mathrm{q}_{\mathrm{P}}(0.57)$ in popA compared to than of the BILs. But in popB, IL $125 \mathrm{~K}$ was the only line which showed higher $\mathrm{q}_{\mathrm{P}}(0.60)$ than that of other BILs and parents (Fig. 2S, supplement).

Leaf thickness and $\mathrm{Chl}$ content: Wide variations were observed for flag leaf thickness in both populations. It ranged from 0.06 (IL 137S) to $0.15 \mathrm{~mm}$ (IL 177S) in popA, while in popB it was the highest in IL $24 \mathrm{~K}(0.16 \mathrm{~mm})$ and lowest in IL $201 \mathrm{~K}(0.07 \mathrm{~mm})$. Thickness showed significant association with $P_{\mathrm{N}}$ and YLDP in both populations. Similarly, Car was maximum in IL 221S [1.52 $\left.\mathrm{mg} \mathrm{g}^{-1}(\mathrm{FM})\right]$ and $201 \mathrm{~K}$ [1.49 $\left.\mathrm{mg} \mathrm{g}^{-1}(\mathrm{FM})\right]$, respectively (Fig. 5).

The Chl content is an important physiological trait which affects the photosynthetic ability of rice. Significant variations were noted for $\mathrm{Chl} a$, Chl $b$, TChl, Chl $a / b$, and Car content among BILs of both populations. Chl $a$ was the highest in IL 75S [3.75 $\left.\mathrm{mg} \mathrm{g}^{-1}(\mathrm{FM})\right]$ and IL $246 \mathrm{~K}$ $\left[3.63 \mathrm{mg} \mathrm{g}^{-1}(\mathrm{FM})\right]$. Chl $b$ content was maximum in IL $230 \mathrm{~S}\left[1.38 \mathrm{mg} \mathrm{g}^{-1}(\mathrm{FM})\right]$ in popA and IL $138 \mathrm{~K}[1.25 \mathrm{mg}$ $\left.\mathrm{g}^{-1}(\mathrm{FM})\right]$ in popB. Likewise, TChl was the highest in IL $75 \mathrm{~S}\left[5.04 \mathrm{mg} \mathrm{g}^{-1}(\mathrm{FM})\right]$ in popA and in IL 246K [4.86 mg $\left.\mathrm{g}^{-1}(\mathrm{FM})\right]$ in popB. The variations for $\mathrm{Chl} a / b$ ranged from 3.63 (IL 177S) to 2.55 (IL 230S) in popA and 1.97 (IL 96K) to 5.04 (IL 236K) in popB (Table $1 \mathrm{~S}$, supplement).

Mesophyll conductance and chloroplast $\mathrm{CO}_{2}$ concentration: Variable J method of Harley et al. (1992) was used to determine the $g_{\mathrm{m}}$. The differences observed for $g_{\mathrm{m}}$ and $C_{\mathrm{c}}$ were significant in both populations. The $g_{\mathrm{m}}$ ranged from 0.09 in IL $65 \mathrm{~S}$ to $0.75 \mathrm{~mol} \mathrm{~m}^{-2} \mathrm{~s}^{-1}$ in IL $177 \mathrm{~S}$ of popA and 0.06 in IL $78 \mathrm{~K}$ to $0.69 \mathrm{~mol} \mathrm{~m}^{-2} \mathrm{~s}^{-1}$ in IL $173 \mathrm{~K}$ of popB. Similarly, $C_{\mathrm{c}}$ ranged from 123.5 (IL 65S) to $254.7 \mu \mathrm{mol} \mathrm{mol}^{-1}$ (IL 14-3S) and 108.1 (IL 96K) to 272.2

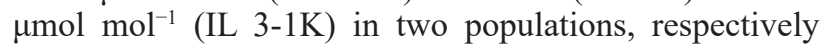
(Fig. 6).

Comparative analysis of yield and yield-related traits in parents and both populations: We compared component traits of grain yield, as well as total dry mass production in parents and both the populations. The mean and range of all phenotypic traits of parents were given in Table 1. All yield-related traits showed significant variations among BILs of both populations except for HI in popB. Plant height $(\mathrm{PH})$, tiller number $(\mathrm{NT})$, and number of panicles per plant (NP) are important yield determinants during the vegetative growth stage. These traits showed highly significant differences in both populations. PH, NT, NP were the highest in $O$. nivara acc. IRGC81848 $(120 \mathrm{~cm}$, 11 , and 10 , respectively) of popA, whereas in popB, $\mathrm{PH}$ was the highest in $O$. nivara acc. IRGC81832 $(117 \mathrm{~cm})$, NT and number of productive tillers were the highest in IL 246K (Table 2S, supplement).

Panicle length (PL) varied from $18 \mathrm{~cm}$ in IL $175 \mathrm{~S}$ to $26.5 \mathrm{~cm}$ in IL $26 \mathrm{~S}$, whereas in popB, it ranged from $17 \mathrm{~cm}$ in IL $78 \mathrm{~K}$ to $24 \mathrm{~cm}$ in IL $250 \mathrm{~K}$. The number of primary branches per panicle (PB) was consistent in both populations, but significant variations were observed for the number of secondary branches per panicle $(\mathrm{SB})$ in popB and popA and it ranged from 12 to 41 (Table 3S), respectively. In popA, maximum number of filled grains (FG) was observed in IL 54S (116), minimum in IL 14-3S (51), and total number of grains per panicle (TNG) was the highest in IL 25S (134) and the lowest in IL 14S (64). However, in popB, IL $75 \mathrm{~K}$ showed maximum of FG and TNG per panicle. The percentage of spikelet fertility (SPF) was $97 \%$ in both populations (Table $4 \mathrm{~S}$, supplement). Panicle mass (PW) and 1,000-grain mass (TGW) were higher in popB than that in popA. The highest PW was observed in IL $24 \mathrm{~K}$ (3.2 g) and TGW in IL 45K (23.8 g), whereas in popA, it was observed in IL 26S (3.0 g) and IL 230S (21.7 g), respectively (Fig. 3S, supplement).

The carbohydrates produced during the process of photosynthesis are translocated to sink (spikelet) which finally determines the grain yield per plant (YLDP). IL 230S showed significantly higher YLDP (8.7 g per plant), and total dry mass (DM) (21.3 g per plant) in popA. However, in popB, the highest YLDP was in IL $75 \mathrm{~K}$ (9.2 g per plant) and DM (23.5 g per plant) in IL $173 \mathrm{~K}$. Harvest index (HI) was significantly different in popA, ranging from 27.3 (IL 64S) to $45.4 \%$ (IL 51S), but it was insignificant in popB (Fig. 4S, supplement).

Principal component analysis (PCA) and correlation: PCA was conducted to estimate the percentage contribution of each trait to the total genetic variation. The results showed that first four components accounted 92 and $93 \%$ of the total genetic variance in popA and popB, respectively. The first $\mathrm{PC}$ accounted about 40 and $43 \%$ of total variation and was strongly associated with $C_{\mathrm{i}}, C_{\mathrm{c}}, \mathrm{FG}$, TNG, and ETR in popA, and $C_{\mathrm{i}}, C_{\mathrm{c}}$, and TNG in popB. The second $\mathrm{PC}$ accounted about 32 and $31 \%$ of variance and was associated with FG and TNG in popA, but with $C_{\mathrm{i}}, \mathrm{ETR}, \mathrm{FG}$, and TNG in popB. The third PC accounted for $12 \%$ of total variation and was positively associated with $\mathrm{FG}, \mathrm{TNG}$, and $C_{\mathrm{c}}$ in popA, while in popB, it was associated with $C_{\mathrm{i}}$. The fourth PC accounted for only 6 and $5 \%$ of total variation and was associated with $C_{\mathrm{i}}, C_{\mathrm{c}}, \mathrm{PH}$, and TNG in popA, and with ETR, SPF, and HI in popB (Table 5S, supplement). The variations among the BILs in both populations based on their Eigen values are shown in Fig. 5S (supplement). 


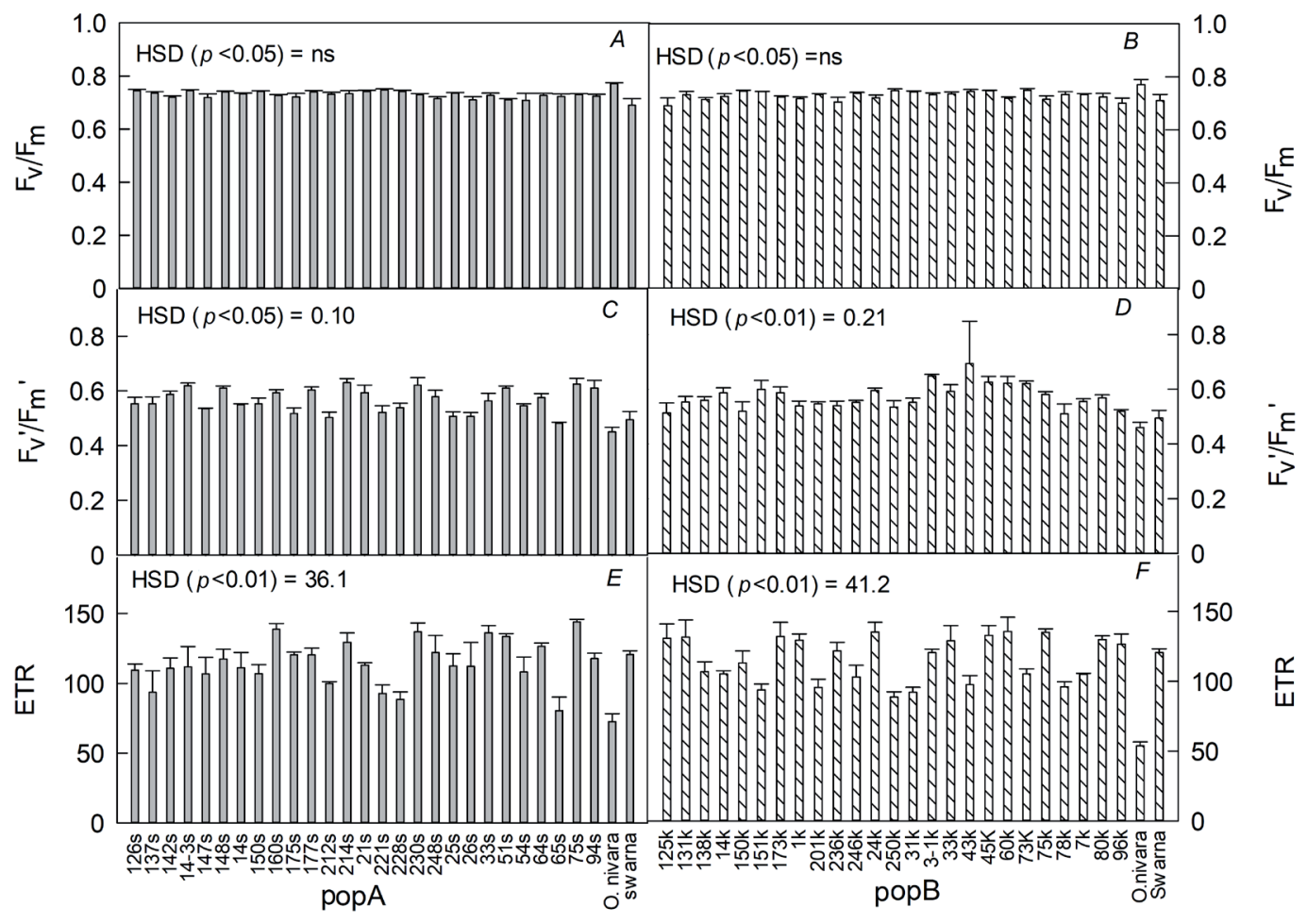

Fig. 3. Variation in important chlorophyll fluorescence traits $\mathrm{F}_{\mathrm{v}} / \mathrm{F}_{\mathrm{m}}(A, B), \mathrm{F}_{\mathrm{v}}{ }^{\prime} / \mathrm{F}_{\mathrm{m}}{ }^{\prime}(C, D)$, and apparent electron transport rate (ETR) (E,F) in two $\mathrm{BC}_{2} \mathrm{~F}_{6}$ populations popA (Swarna $\times$ O. nivara $\mathrm{IRGC81848)}$ and popB (Swarna $\times O$. nivara IRGC81832). Each bar represents the mean of three replications $\pm \mathrm{SD}$.

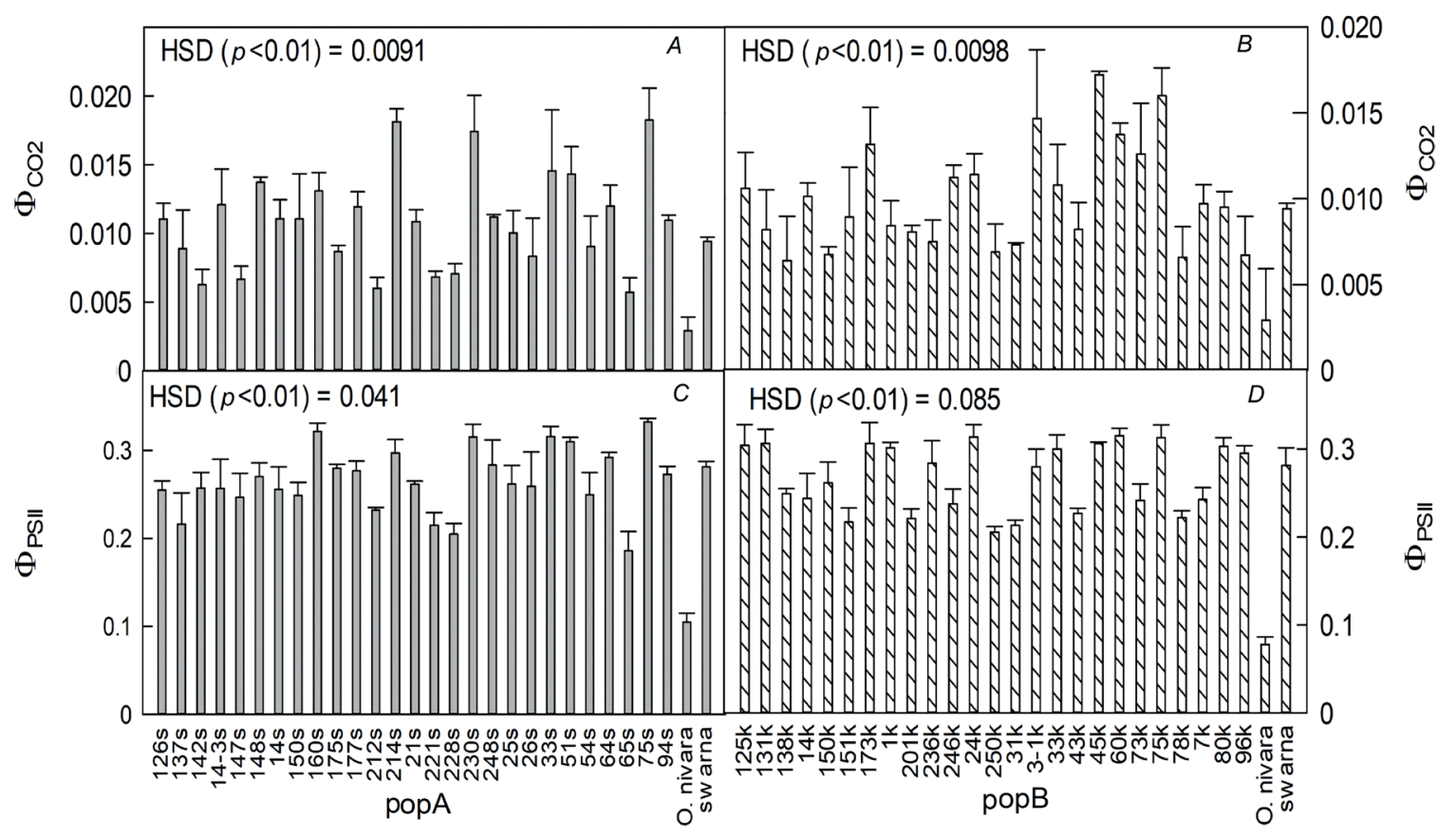

Fig. 4. Variation in important chlorophyll fluorescence traits effective quantum yield of PSII photochemistry $\left(\Phi_{\mathrm{PSII}}\right)(A, B)$, and quantum yield of carboxylation rate $\left(\Phi_{\mathrm{CO} 2}\right)(C, D)$ in two $\mathrm{BC}_{2} \mathrm{~F}_{6}$ populations popA (Swarna $\times O$. nivara $\left.\mathrm{IRGC} 81848\right)$ and popB $(\mathrm{Swarna} \times$ O. nivara IRGC81832). Each bar represents the mean of three replications $\pm \mathrm{SD}$.

Marker allele constitution of BILs: The percentage of homozygous $O$. nivara allele introgressions was higher in popA than that in popB. It ranged from 0.0 (IL 54S) to 24.7 (IL 14S) with an average introgression of 11.5 in popA. However, in popB, the percentage of homozygous O. nivara introgressions ranged from 2.7 (ILs $45 \mathrm{~K}, 75 \mathrm{~K}$ 


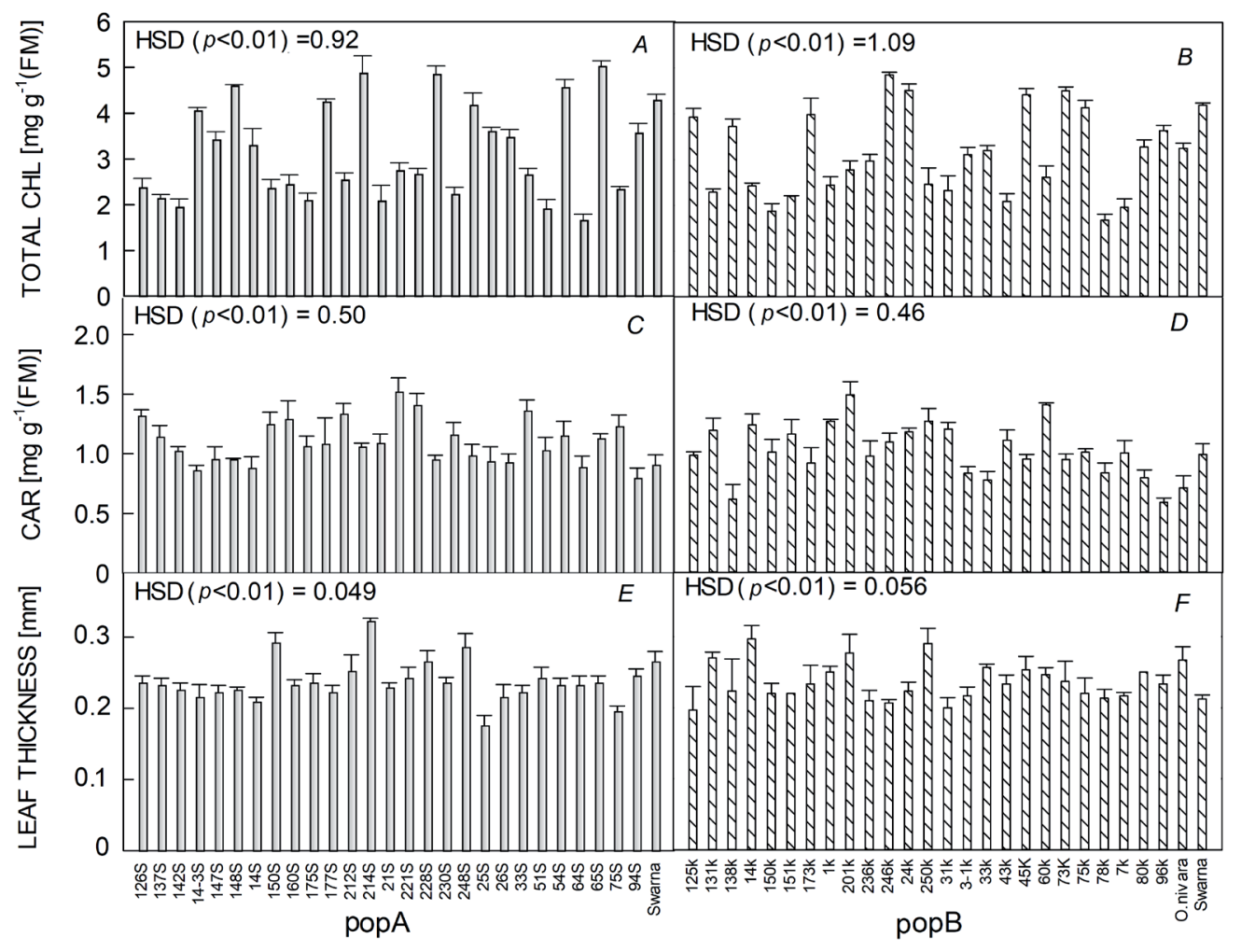

Fig. 5. Variation in total chlorophyll $(\mathrm{Chl})(A, B)$, carotenoid content (Car) $(C, D)$ and flag leaf thickness $(E, F)$ in two $\mathrm{BC}_{2} \mathrm{~F}_{6}$ populations Pop $A$ (Swarna $\times O$. nivara IRGC81848) and Pop $B($ Swarna $\times O$. nivara IRGC81832). Each bar represents the mean of three replications $\pm \mathrm{SD}$.

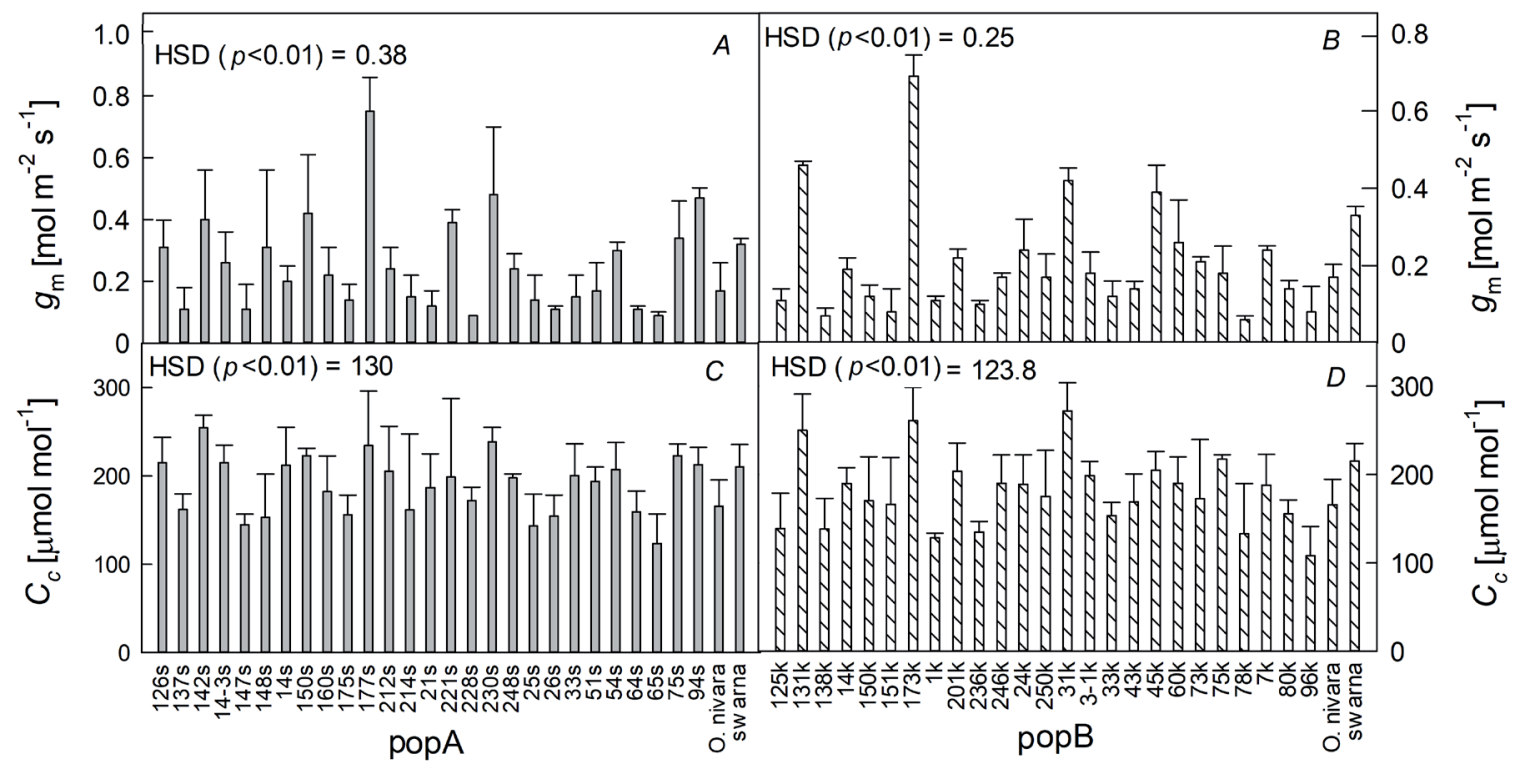

Fig. 6. Variation in mesophyll conductance $\left(g_{\mathrm{m}}\right)(A, B)$ and chloroplast $\mathrm{CO}_{2}$ concentration $\left(C_{c}\right)(C, D)$ in two $\mathrm{BC}_{2} \mathrm{~F}_{6}$ populations popA $($ Swarna $\times O$. nivara IRGC81848) and popB (Swarna $\times$ O. nivara IRGC81832). Each bar represents the mean of three replications $\pm \mathrm{SD}$.

and $201 \mathrm{~K}$ ) to 16.4 (IL $250 \mathrm{~K}$ ) with a mean introgression of 8.7. Likewise, heterozygosity was also higher in popA $(6.5 \%)$ than that in popB $(3.8 \%)$.
Marker-trait association: A total of 73 polymorphic SSR markers covering all chromosomes were used to genotype all 52 BILs. Single marker analysis showed that 
Table 1. Descriptive statistics for 18 phenotypic traits in parents IRGC81832, IRGC81848 and Swarna (mean \pm SE, $n=3$ ). PH - plant height; FLL - flag leaf length; FLW - flag leaf width; FLA - flag leaf area; NT - number of tillers per plant; NP - number of panicles per plant; PL - panicle length; PB - primary branches per panicle; SB - secondary branches per panicle; FG - filled grains; YLDP - yield/ plant; BM - biomass; DM - total dry mass; HI - harvest index. The means and SDs should have the same numper of decimal places!

\begin{tabular}{llll}
\hline Variable & Oryza nivara (IRGC81832) & Oryza nivara (IRGC81848) & Swarna \\
\hline PH & $116.97 \pm 2.0$ & $119.97 \pm 9.39$ & $80.67 \pm 1.15$ \\
FLL & $46.7 \pm 4.86$ & $43 \pm 9.20$ & $24.53 \pm 0.90$ \\
FLW & $1.4 \pm 0.06$ & $1.43 \pm 0.12$ & $1.43 \pm 0.06$ \\
FLA & $49.2 \pm 6.82$ & $46.43 \pm 12.72$ & $26.2 \pm 0.10$ \\
NT & $9 \pm 0.58$ & $11 \pm 2.65$ & $6.33 \pm 0.58$ \\
NP & $9 \pm 0.58$ & $10 \pm 3.61$ & $5.33 \pm 0.58$ \\
PL & $23.97 \pm 0.33$ & $21.97 \pm 1.05$ & $21.73 \pm 1.31$ \\
PB & $7 \pm 0$ & $5 \pm 1.00$ & $10 \pm 1.00$ \\
SB & $10 \pm 0.58$ & $10 \pm 1.00$ & $22 \pm 1.00$ \\
FG & $25 \pm 1.73$ & $30 \pm 2.00$ & $82.33 \pm 11.68$ \\
TNG & $30.67 \pm 2.60$ & $40 \pm 3.00$ & $112.33 \pm 2.52$ \\
SPF & $81.73 \pm 1.44$ & $75.03 \pm 0.65$ & $73.17 \pm 9.11$ \\
PW & $0.93 \pm 0.03$ & $0.97 \pm 0.06$ & $1.83 \pm 0.15$ \\
TGW & $9.5 \pm 0.29$ & $9.87 \pm 0.78$ & $17.6 \pm 0.53$ \\
YLDP & $1.8 \pm 0.47$ & $2.5 \pm 0.50$ & $4.4 \pm 0.53$ \\
BM & $16 \pm 2.65$ & $13.67 \pm 2.31$ & $11 \pm 1.00$ \\
DM & $17.8 \pm 2.74$ & $16.17 \pm 2.36$ & $13 \pm 2.00$ \\
HI & $10.5 \pm 3.02$ & $15.67 \pm 3.47$ & $34.47 \pm 6.73$ \\
\hline
\end{tabular}

47 markers in popA and 48 in popB were significantly associated with more than one trait, indicating pleiotropic effect/linkage (Table 6S, supplement). Particularly, in popA, RM514 on chromosome 3 was associated with a maximum of 13 traits and RM85 was associated with 5 traits. There were three such markers on chromosome 2. RM48 was associated with seven traits $\left(P_{\mathrm{N}}, \mathrm{CE}, g_{\mathrm{m}}, C_{\mathrm{c}}\right.$, Chl $b$, Chl $a / b$, YLDP); RM250 with six traits $\left(P_{\mathrm{N}}, \mathrm{E}\right.$, $\left.\mathrm{CE}, \mathrm{F}_{\mathrm{v}}{ }^{\prime} / \mathrm{F}_{\mathrm{m}}{ }^{\prime}, \mathrm{q}_{\mathrm{N}}, \mathrm{PH}\right)$ and $\mathrm{RM} 263$ with five traits $(E$, WUE, Chl $a / b$, NP, and PB). Another marker, RM209 on chromosome 11, showed significant association with five traits $\left(E\right.$, WUE, CE, $C_{\mathrm{c}}, \mathrm{F}_{\mathrm{v}} / \mathrm{F}_{\mathrm{m}}$, and $\left.\mathrm{PH}\right)$.

Further analysis in popB showed that RM204 on chromosome 6 showed association with maximum of six traits namely $P_{\mathrm{N}}, C_{\mathrm{i}}, E, g_{\mathrm{s}}, \Phi_{\mathrm{CO} 2}$, and $\mathrm{q}_{\mathrm{N}}$. Likewise, RM488 on chromosome 1, RM185 on chromosome 4 were associated with six traits each. Similarly, RM122 on chromosome 5 was associated with five traits, i.e., $g_{\mathrm{s}}, C_{\mathrm{i}}$, $\Phi_{\mathrm{CO} 2}, \mathrm{TNG}$, and YLDP. There was no common association in both populations.

Multi-trait correlation: Significant correlations were obtained between different physiological and yield-related traits. $P_{\mathrm{N}}$ showed significant positive correlation at $1 \%$ level with $g_{\mathrm{s}}, E, \mathrm{CE}, C_{\mathrm{c}}$, leaf thickness, $\Phi_{\mathrm{PSII}}, \Phi_{\mathrm{CO} 2}, \mathrm{ETR}$, YLDP, BM, DM, and HI. On the contrary, it showed a significant negative correlation with $\mathrm{q}_{\mathrm{N}}$ in both populations (Fig. 7). However, leaf $\mathrm{Chl}$ content showed a positive correlation with $P_{\mathrm{N}}$ at 1 and $5 \%$ significance level in popA and popB, respectively.

\section{Discussion}

Wild relatives of cultivated rice are an important genetic reservoir which offers novel genes for enhancing crop yield and maintaining future food security. Previous studies on rice have shown that $P_{\mathrm{N}}$ was higher in wild species O. nivara $100097\left[24.2 \mu \mathrm{mol}\left(\mathrm{CO}_{2}\right) \mathrm{m}^{-2} \mathrm{~s}^{-1}\right]$ and O. longistaminata IR105262 [22.9 $\mu \mathrm{mol}\left(\mathrm{CO}_{2}\right) \mathrm{m}^{-2} \mathrm{~s}^{-1}$ ] than that in cultivars and hybrids (Kiran et al. 2013, Kondamudi et al. 2016). However, Xiong et al. (2017) showed that the wild species $O$. latifolia had the highest $P_{\mathrm{N}}\left[35.9 \mu \mathrm{mol}\left(\mathrm{CO}_{2}\right) \mathrm{m}^{-2} \mathrm{~s}^{-1}\right]$ than any other wild and cultivated species of Oryza. Nevertheless, Giuliani et al. (2013) reported that African cultivated rice O. glaberrima showed the highest $P_{\mathrm{N}}\left[27.09 \mu \mathrm{mol}\left(\mathrm{CO}_{2}\right) \mathrm{m}^{-2} \mathrm{~s}^{-1}\right]$, followed by wild species $O$. glumaepatula $\left[25.8 \mu \mathrm{mol}\left(\mathrm{CO}_{2}\right) \mathrm{m}^{-2} \mathrm{~s}^{-1}\right]$. The BILs derived from wild species $O$. rufipogon and elite cultivar (KMR3) also showed a significant improvement in $P_{\mathrm{N}}$, grain yield, and dry mass (Haritha et al. 2017). In this study, IL $230 \mathrm{~S}$ from popA showed the highest $P_{\mathrm{N}}$ of $23.1 \mu \mathrm{mol}\left(\mathrm{CO}_{2}\right) \mathrm{m}^{-2} \mathrm{~s}^{-1}$ and IL $173 \mathrm{~K}$ from popB showed $21.5 \mu \mathrm{mol}\left(\mathrm{CO}_{2}\right) \mathrm{m}^{-2} \mathrm{~s}^{-1}$. Considering two populations, a total of 10 BILs showed higher $P_{\mathrm{N}}$ than their parents Swarna and O. nivara. Masumoto et al. (2004) reported that around $14-15 \%$ of $\mathrm{BC}_{2}$ population derived from $O$. sativa $\times O$. rufipogon had higher oxygen evolution rates than their parents. $P_{\mathrm{N}}$ increases with increasing $g_{\mathrm{s}}$ (Ono et al. 2013). High $g_{\mathrm{s}}$ was reported in wild species O. longistaminata IR105262 (Kiran et al. 2013). In the present study, $g_{\mathrm{s}}$ was found to be the highest in IL $51 \mathrm{~S}$ of popA and IL $75 \mathrm{~K}$ of popB. Notably, as many as 27 BILs 


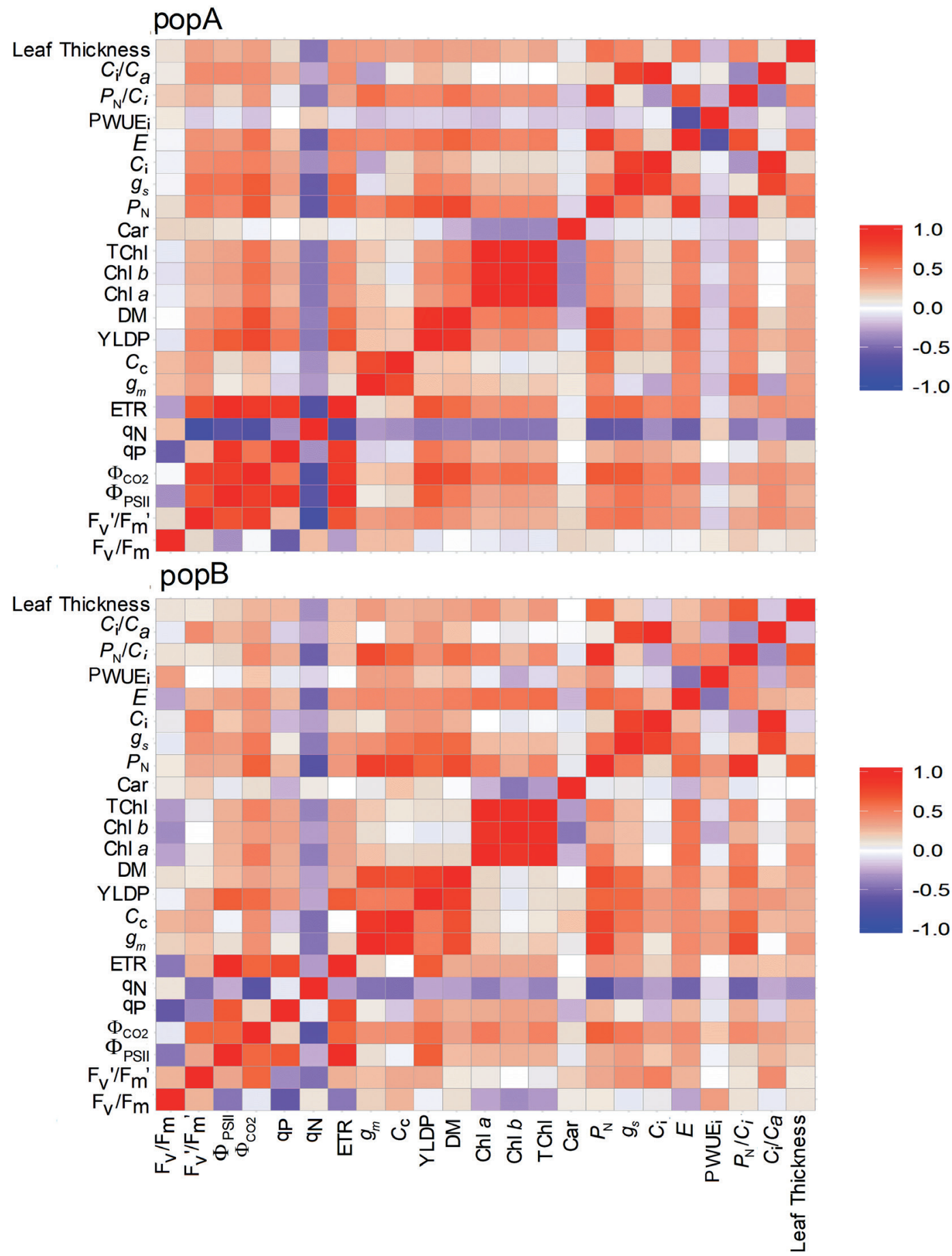

Fig. 7. Heat map of Pearson's correlation coefficients between morphological, physiological, and yield related traits in two $\mathrm{BC}_{2} \mathrm{~F}_{6}$ populations of Swarna $\times O$. nivara. The squares with red color indicate positive $(p<0.05)$ correlation and squares with blue color indicate negative $(p<0.05)$ correlations. $C_{i} / C_{\mathrm{a}}$ - ratio between intercellular $\mathrm{CO}_{2}\left(C_{\mathrm{i}}\right)$ and ambient $\mathrm{CO}_{2}\left(C_{\mathrm{a}}\right) ; P_{\mathrm{N}} / C_{\mathrm{i}}-$ carboxylation efficiency; $\mathrm{WUE}_{\mathrm{i}}$ - photosynthetic water-use efficiency; $E$ - transpiration rate; $C_{\mathrm{i}}$ - intercellular $\mathrm{CO}_{2}$ concentration; $g_{\mathrm{s}}$ - stomatal conductance; $P_{\mathrm{N}}-$ net photosynthetic rate; Car - carotenoid content; TChl - total chlorophyll content; Chl - chlorophyll; DM - dry mass; YLDP - grain yield per plant; $C_{c}$ - chloroplast $\mathrm{CO}_{2}$ concentration; $g_{\mathrm{m}}$ - mesophyll conductance; ETR - electron transport rate; $\mathrm{q}_{\mathrm{N}}-$ nonphotochemical quenching coefficient; $\mathrm{q}_{\mathrm{P}}$ - photochemical quenching coefficient; $\Phi_{\mathrm{CO} 2}-$ quantum yield of carboxylation rate; $\Phi_{\mathrm{PSII}}-$ effective quantum yield of PSII photochemistry; $F_{v} / F_{m}-$ maximum photochemical efficiency of PSII; $F_{v}{ }^{\prime} / F_{m}{ }^{\prime}-$ maximum quantum yield of PSII after light adaptation. 
showed higher $g_{\mathrm{s}}$ than the parents and 9 of these BILs showed high $P_{\mathrm{N}}$ as well.

Kiran et al. (2013) reported that the wild species $O$. nivara 100097 showed maximum $E\left[11.1 \mathrm{mmol}\left(\mathrm{H}_{2} \mathrm{O}\right)\right.$ $\mathrm{m}^{-2} \mathrm{~s}^{-1}$. Our previous report showed that $P_{\mathrm{N}}$ was positively correlated with $E$ (Haritha et al. 2017). However, $E$ showed an inverse relation with leaf thickness, but WUE showed positive relation with leaf thickness among the wild and cultivated species of Oryza (Giuliani et al. 2013). Similarly, the maximum $C_{\mathrm{i}}$ was observed in IL $33 \mathrm{~S}$ [343.5 $\left.\mu \mathrm{mol}\left(\mathrm{CO}_{2}\right) \mathrm{mol}^{-1}\right]$ and IL $3-1 \mathrm{~K}$ from both populations, respectively. The highest value $\left[280 \mu \mathrm{mol}\left(\mathrm{CO}_{2}\right)\right.$ $\mathrm{mol}^{-1}$ ] reported previously was in O. rufipogon IR103404 (Kiran et al. 2013). The derived BILs of Swarna and $O$. nivara showed higher gas-exchange rate than that of KMR3 $\times O$. rufipogon BILs in terms of $P_{\mathrm{N}}, g_{\mathrm{s}}, C_{\mathrm{i}}$, and $E$ (Haritha et al. 2017). CE showed significant positive association with $P_{\mathrm{N}}$ in both populations. WUE is another important trait for dry matter production. This was determined by $P_{\mathrm{N}}$ and $E$. During the water-deficit conditions, stomatal closure reduces the loss of water from leaf, which leads to an increase in photosynthetic WUE. It was positively associated with leaf stomatal density (Xu et al. 2008), photosynthesis, and stomatal conductance (Silva et al. 2013). The highest WUE of $4.69 \mu \mathrm{mol} \mathrm{mmol}{ }^{-1}$ in different species of Oryza was reported by Giuliani et al. (2013). In our previous report, we showed that the IL 106 derived from KMR3 $\times$ O. rufipogon showed high WUE of $3.43 \mu \mathrm{mol} \mathrm{mmol}{ }^{-1}$. However, in present study, the maximum WUE was $3.06 \mu \mathrm{mol}\left(\mathrm{CO}_{2}\right) \mathrm{mmol}^{-1}\left(\mathrm{H}_{2} \mathrm{O}\right)$ in IL $26 \mathrm{~S}$, which was higher than the other wild and cultivated species of Oryza $\left(2.0 \mu \mathrm{mol} \mathrm{mmol}{ }^{-1}\right)$ (Kiran et al. 2013). WUE and $W_{U} E_{i}$ showed significant variations among the ILs but these were not significantly correlated with the yield-related traits.

On the other hand, $g_{\mathrm{m}}$ and $C_{\mathrm{c}}$ plays a crucial role in the diffusion of $\mathrm{CO}_{2}$ from sub-stomatal cavities to the site of carboxylation in chloroplast stroma which limits photosynthesis and grain yield in rice (Flexas et al. 2008). Our results revealed that 7 BILs of popA showed higher $g_{\mathrm{m}}$ and 9 BILs showed higher $C_{\mathrm{c}}$ than parents and in these 6 BILs $(230 \mathrm{~S}, 177 \mathrm{~S}, 94 \mathrm{~S}, 150 \mathrm{~S}, 14-3 \mathrm{~S}$, and $75 \mathrm{~S})$ were common. However, popB showed slightly lower $g_{\mathrm{m}}$ than that of popA, but 3 BILs $(173 \mathrm{~K}, 131 \mathrm{~K}$, and $3-1 \mathrm{~K})$ showed high $g_{\mathrm{m}}$ and $C_{\mathrm{c}}$. Giuliani et al. (2013) reported high $g_{\mathrm{m}}$ of $0.467 \mathrm{~mol} \mathrm{~m}^{-2} \mathrm{~s}^{-1}$ in $O$. australiensis and high $C_{\mathrm{c}}$ $0.185 \mu \mathrm{mol} \mathrm{mol}{ }^{-1}$ in $O$. glaberrima. $P_{\mathrm{N}}$ showed a strong positive association with $g_{\mathrm{m}}$ at a significance of $5 \%$ in popA and $1 \%$ in popB. Similarly, $C_{\mathrm{c}}$ also showed positive association with $P_{\mathrm{N}}$ at $1 \%$ level of significance. The positive interrelations among the traits $P_{\mathrm{N}}, E, g_{\mathrm{s}}$, and $g_{\mathrm{m}}$ were also reported by Giuliani et al. (2013).

Leaf thickness affects the photosynthetic components per unit leaf area (Murchie et al. 2005). This is an important leaf structural trait, which determines the yield capacity of rice. It is positively correlated with $P_{\mathrm{N}}$ largely because of a high Chl content in thicker leaves (Rahman et al. 2013). Our results showed significant positive association of leaf thickness with $P_{\mathrm{N}}$ in both populations. Recent study of Guru et al. (2017) reported that IL 24K had the highest flag leaf length compared to other lines and hybrids. Takai et al. (2010) showed that SPAD and specific leaf area (SLA) play a major role in increasing photosynthesis by increasing the leaf Chl content and leaf thickness. Our results showed the leaf Chl content was positively associated with $P_{\mathrm{N}}$ and it was the highest in IL 75S of popA and in IL 246K of popB. Leaf Chl fluorescence is used to assess the PSII photochemistry, energy absorption, and dissipation of excess energy by PSII (Falqueto et al. 2009). Significant positive associations were found between $P_{\mathrm{N}}$ and $\mathrm{F}_{\mathrm{v}}{ }^{\prime} / \mathrm{F}_{\mathrm{m}}{ }^{\prime}, \Phi_{\mathrm{PSII}}$, and $\Phi_{\mathrm{CO} 2}$, as well as negative association with $\mathrm{q}_{\mathrm{N}}$ in both populations. Hura et al. (2009) showed significant associations between Chl fluorescence traits, yield, and leaf gas-exchange parameters of triticale. However, $\mathrm{F}_{\mathrm{v}} / \mathrm{F}_{\mathrm{m}}$ showed positive correlation with $P_{\mathrm{N}}, g_{\mathrm{s}}$, and $E$ and negative correlation with $C_{\mathrm{i}}$ in triploid popular hybrid clones of Populus simonii and Populas nigra (Zhao et al. 2015) Maxwell and Johnson (2000) suggested that $\Phi_{\text {PSII }}$ can provide useful information concerning photosynthetic performance in the field. However, fluorescence measurements alone cannot be used to make comparative measurements of photosynthesis in plants.

$P_{\mathrm{N}}$ showed the significant positive association with YLDP, BM, DM, and HI. As an example, IL 230S, which had high $P_{\mathrm{N}}$, showed the high yield $(8.7 \mathrm{~g})$, high BM $(12.6 \mathrm{~g})$, and high DM (21.3 g). Our previous report showed that $P_{\mathrm{N}}$ is associated with DM (Haritha et al. 2017). High yield in modern cultivars is associated with biomass (Alvarez et al. 2012), 1,000-grain mass (Bhatia et al. 2017), number of filled grains per panicle (Bhatia et al. 2017), panicle size (Laza et al. 2004), and a tiller number per plant (Yeh et al. 2015). The component traits of yield in relation to photosynthesis showed significant positive association with NT, PB, and TGW.

The impact of all physiological and yield component traits to the total genetic variation is determined by PCA. In current study, the percentage of cumulative variance explained by four principal components (PC) was $92 \%$ in popA, and $93 \%$ in popB indicating there may be a strong correlation among the traits to explain gross diversity. Interestingly, FG and TNG in popA and $C_{\mathrm{i}}$ in popB were common contributing traits for first three PCs. However, considering both populations together, TNG was common to all PCs in both populations. Nachimuthu et al. (2014) reported $80.6 \%$ of genetic variation explained by the first five PCs, and suggested days to $50 \%$ flowering, days to maturity, PH, NT, SPF, PL, and grain length as important for classifying the variation in a set of 192 genotypes of rice. Likewise, Gana et al. (2013) also reported 65\% of variation explained by five PCs and leaf width, TNG, gall count, and PL showed more contribution to a total genetic variation.

RM514 was significantly associated with as many as 13 traits, $P_{\mathrm{N}}, E$, WUE, WUE, $, C E, \mathrm{~F}_{\mathrm{v}}{ }^{\prime} / \mathrm{F}_{\mathrm{m}}{ }^{\prime}, \Phi_{\mathrm{PSII}}, \Phi_{\mathrm{CO} 2}, \mathrm{q}_{\mathrm{N}}$, ETR, Chl $a$, NP, and TGW. Of these $\mathrm{F}_{\mathrm{v}}{ }^{\prime} / \mathrm{F}_{\mathrm{m}}{ }^{\prime}$ and $E$ were strongly associated at significance level of 0.01 and $0.1 \%$ with a phenotypic variance of 46.2 and $42.2 \%$, respectively. Likewise, $P_{\mathrm{N}}, \Phi_{\mathrm{PSII}}, \Phi_{\mathrm{CO} 2}, \mathrm{q}_{\mathrm{N}}$, and ETR showed association at $1 \%$ and explained the phenotypic variance of $25.3,24.9,25.8,34.1$, and $25.2 \%$, respectively. All 
other traits were associated at a significance level of $5 \%$. Previous reports showed that RM514 flanks a QTLs linked to panicle length (Wang et al. 2012), number of filled grains per panicle (Sellamuthu et al. 2015), and grain yield, thousand-grain mass under water-stress conditions (Zou et al. 2005). RM85, another marker on chromosome 3 , was significantly associated with five traits, $P_{\mathrm{N}}, E, \mathrm{~F}_{\mathrm{v}}{ }^{\prime} /$ $\mathrm{F}_{\mathrm{m}}{ }^{\prime}, \Phi_{\mathrm{PSII}}$, and ETR. It has been reported as flanking marker for QTL qNSB3.1 for number of secondary branches, ac3.2 for amylose content (Swamy et al. 2011, 2012), and spikelet number per panicle (Xu et al. 2004). Thus, these two markers are important to track several traits in marker-assisted selection and breeding.

$\mathrm{RM} 250$ is linked to $P_{\mathrm{N}}, E, \mathrm{CE}, \mathrm{F}_{\mathrm{v}}{ }^{\prime} / \mathrm{F}_{\mathrm{m}}{ }^{\prime}, \mathrm{q}_{\mathrm{N}}$, and $\mathrm{PH}$, and the marker was reported to be related to most of the yieldrelated traits in $\mathrm{BC}_{2} \mathrm{~F}_{2}$ (Swamy et al. 2011). It flanks $n s p 2.1$ for number of spikelets per plant, $n s p 2.1$ for number of filled grains per plant, $b m 2.1$ for vegetative biomass, $y l d 2.1$ for yield per plant, wup2.1 for water uptake, and gc2.1 for gel consistency (Swamy et al. 2012, 2014), QPh2 for plant height (Xu et al. 2005), qSBN-2ci for secondary branches number (Mei et al. 2006), and panicle number (Zou et al. 2005). RM48 showed epistatic QTL interactions, it was linked to the QTL tp2 for number of tillers per plant and gwlc for grain mass (Xing et al. 2002). In our experimnet, it was linked with four physiological traits $P_{\mathrm{N}}, C_{\mathrm{c}}, \mathrm{Chl} b$, $\mathrm{Ch} a / b$, and YLDP. Many studies showed that RM263 is significantly associated with yield and yield-related traits, hgw2 for heterotic loci linked to 1,000-grain mass (Luo et al. 2011), yld2.1 for yield per plant (Marri et al. 2005), and $q H D-2$ for heading date (Zou et al. 2000). In our study, RM263 was significantly associated with yield-related traits, such as NP, PB, and also to physiological traits $E$, WUE, and $\mathrm{Chl} a / b$ and they were significantly correlated with $P_{\mathrm{N}}$. This has not been reported previously. Likewise, another marker RM209 was significantly associated with $E$ and WUE, whereas $C_{\mathrm{c}}, \mathrm{F}_{\mathrm{v}} / \mathrm{F}_{\mathrm{m}}$, and $\mathrm{PH}$ were associated at 5\% level of significance. Also, RM209 was reported to be associated with $Q G y 11 a$ for grain yield per plant (Xu et al. 2005), nt 11.1 for number of tillers per plant, $b m 11.1$ for vegetative biomass, $y l d p 11.1$ for yield per plant (Swamy et al. 2011), mp11.1 for milling percent, asv11.1 for alkali spreading value, and $g c 11.1$ for gel consistency (Swamy et al. 2012) and protein content (Xu et al. 2016).

Furthermore, the analysis of marker trait association in popB showed RM488 on chromosome 1 was associated with $\mathrm{F}_{\mathrm{v}} / \mathrm{F}_{\mathrm{m}}, \mathrm{Chl} b, \mathrm{Chl} a / b, \mathrm{PL}$, and PWT. Previous reports showed that RM488 was linked with the QTL ph1.1 for plant height, npt1.1 for number of productive tillers per plant, $n s p 1.1$ for number of spikelets per plant, $n f g 1.1$ for number of filled grains per plant (Swamy et al. 2014), qNSB1.1 for number of secondary branches (Swamy et al. 2011), mpl.1 for milling percent, $k w 1.3$ for kernel width, verl.1 for volume expansion ratio (Swamy et al. 2012), ph1.3 for plant height, $n t 1.3$ for number of tillers per plant, np1.2 for number of panicles per plant, pll.2 for panicle length, nsp1.1 for number of spikelets per plant, gnp1.1 for number of grains per plant, and gw1.6 for grain mass (Kaladhar et al. 2008). Likewise, RM185 on chromosome 4 was associated with six traits with the significance level at $5 \%$. It was reported to be associated with days to heading ( $q D T H 4.1$ ), days to 50\% flowering ( $q D F F 3.2$ ), days to maturity (dtm4.1), kernel width $(k w 4.1)$, and gel consistency (gc4.1) (Swamy et al. 2011, 2012, 2014). But in our study, it was highly associated with leaf pigmentrelated traits, such as Chl $a, \mathrm{Chl} b$, TChl, Car, and yieldcomponent traits, NT and TGW. RM122 on chromosome 5 is associated with $g_{\mathrm{s}}, C_{\mathrm{i}}, \Phi_{\mathrm{PSII}}, \mathrm{TNG}$, and YLDP. It was linked to BLB resistance gene $X a 5$ in rice genotypes (Sabar et al. 2016) and lemma width (Ishikawa et al. 2017). RM204 on chromosome 6 was associated with $P_{\mathrm{N}}, g_{\mathrm{s}}, C_{\mathrm{i}}$, $E$, $\Phi_{\mathrm{PSII}}$, and $\mathrm{q}_{\mathrm{N}}$. Swamy et al. (2011) showed that RM204 was linked to QTL $q D T H 6.1$ for days to heading, $q D F F 4.1$ for days to $50 \%$ flowering, qSD6.1 for stem diameter. It was linked to $n s 6.1$ for number of spikelets per panicle, gp6.1 for number of grains per panicle (Kaladhar et al. 2008), and kw6.1 for kernel width (Swamy et al. 2012). Another marker RM162 on chromosome 6 was linked to five traits WUE, WUE $, \Phi_{\mathrm{CO} 2}, \mathrm{~PB}$, and TGW. Previous reports showed that it was linked to the QTL for $q C C 6 b$ for Chl content (Hu et al. 2009), qNT-6 for number of tillers per plant (Zhou et al. 2013), qPBN-6 for primary branch number (Liu et al. 2008), and $q T P H-6$ for tallest panicle height (Ma et al. 2009).

All the markers, which showed significant association with photosynthetic traits, were previously reported to be linked with yield traits, indicating their pleiotropic effect or strong trait correlation. Interestingly, we did not find any common associated marker for yield or photosynthesis related-traits studied in both populations, indicating marker-trait association varies continuously in different interspecific populations. Though, these two populations were derived from common genetic background of Swarna.

Conclusions: The results showed that wide variations in leaf photosynthetic traits, physiological, yield and yield-related traits among the BILs. $P_{\mathrm{N}}$ was significantly correlated with $g_{\mathrm{s}}, E, g_{\mathrm{m}}, C_{\mathrm{c}}, \mathrm{CE}$, leaf thickness, TChl, $\mathrm{F}_{\mathrm{v}}{ }^{\prime} / \mathrm{F}_{\mathrm{m}}{ }^{\prime}, \Phi_{\mathrm{PSII}}, \Phi_{\mathrm{CO} 2}$, YLDP, BM, DM, and HI in both populations. Four BILs (IL 230S, IL 75S, IL 214S, and IL 33S) from popA and six BILs (173K, 3-1K, 24K, 45K, $75 \mathrm{~K}$, and $131 \mathrm{~K}$ ) from popB showed higher $P_{\mathrm{N}}$ than that of parents. These BILs also showed high $g_{\mathrm{s}}, C_{\mathrm{i}}, g_{\mathrm{m}}, C_{\mathrm{c}}$, leaf thicknes, TChl, ETR, TGW, YLDP, and DM. The principal component analysis showed the first four PCs explained 92 and $93 \%$ of total genetic variation in popA and popB, respectively. These principal components are significantly associated with the traits $C_{\mathrm{i}}, C_{\mathrm{c}}, \mathrm{FG}$, and TNG. Similarly, single marker analysis showed six markers from popA and five markers from popB that were associated with more than five traits indicating pleiotropic effect. These loci are of great importance in improving photosynthetic traits and should be explored in detail for further use in crop improvement. This study helped identify the factors which contribute to photosynthesis and the relation among various gas-exchange and yield-related traits. Further, it shows that introgressions from wild species can help increase several traits. The BILs with high $P_{\mathrm{N}}, \mathrm{DM}$, and grain yield can be used to improve a yield potential in modern cultivars. 


\section{References}

Adachi S., Nakae T., Uchida M. et al.: The mesophyll anatomy enhancing $\mathrm{CO}_{2}$ diffusion is a key trait for improving rice photosynthesis. - J. Exp. Bot. 64: 1061-1072, 2013.

Al-Tahir F.M.M.: Flag leaf characteristics and relationship with grain yield and grain protein percentage for three cereals. $-\mathrm{J}$. Med. Plants Stud. 2: 1-7, 2014.

Alvarez R.D.C.F., Crusciol C.A.C., Nascente A.S. et al:: Gas exchange rates, plant height, yield components, and productivity of upland rice as affected by plant regulators. - Pesqui. Agropecu. Bras. 47: 1455-1461, 2012.

Arbelaez J.D., Moreno L.T., Singh N. et al.: Development and GBS-genotyping of introgression lines (BILs) using two wild species of rice, O. meridionalis and $O$. rufipogon, in a common recurrent parent, $O$. sativa cv. Curinga. - Mol Breed. 35: 81, 2015.

Bessho-Uehara K., Furuta T., Masuda K. et al.: Construction of rice chromosome segment substitution lines harboring Oryza barthii genome and evaluation of yield-related traits. - Breed Sci. 67: 408-415, 2017.

Bhatia D., Joshi S., Das A. et al.: Introgression of yield component traits in rice (Oryza sativa ssp. indica) through interspecific hybridization. - Crop Sci. 57: 1557-1573, 2017.

Björkman O., Demmig B.: Photon yield of $\mathrm{O}_{2}$ evolution and chlorophyll fluorescence characteristics at $77 \mathrm{~K}$ among vascular plants of diverse origins. - Planta 170: 489-504, 1987.

Chen W.F., Xu Z.J., Zhang B.L.: Physiological Bases of Super High Yield Breeding in Rice. Pp. 123-150. Liao Ning Science Technol. Publ. Company, Shenyang 1995.

Ding Z., Li T., Zhu X. et al.: Three photosynthetic patterns characterized by cluster analysis of gas exchange data in two rice populations. - Crop J. 2: 22 -27, 2014.

de Mendiburu F.: Agricolae: Statistical procedures for agricultural research. R package version 1.2-4. http:// CRAN.Rproject.org/package=agricolae, 2012.

Eizenga G.C., Neves P.C.F., Bryant R.J. et al.: Evaluation of a M-202 $\times$ Oryza nivara advanced backcross mapping population for seedling vigor, yield components and quality. Euphytica 208: 157-171, 2016.

Eizenga G.C., Sanchez P.L., Jackson A.K. et al.: Genetic variation for domestication-related traits revealed in a cultivated rice, Nipponbare (Oryza sativa ssp. japonica) $\times$ ancestral rice, $O$. nivara, mapping population. - Mol. Breed. 37: 135, 2017.

Falqueto A.R., Cassol D., Magalhães Júnior A.M.D. et al.: Physiological analysis of leaf senescence of two rice cultivars with different yield potential. - Pesqui. Agropecu. Bras. 44: 695-700, 2009.

Flexas J., Ribas-Carbó M, Diaz-Espejo A. et al.: Mesophyll conductance to $\mathrm{CO}_{2}$ : current knowledge and future prospects. - Plant Cell Environ. 31: 602-621, 2008.

Gaikwad K.B., Singh N., Bhatia D. et al.: Yield-enhancing heterotic QTL transferred from wild species to cultivated rice Oryza sativa L. - PLoS ONE 9: e96939, 2014.

Gana A.S., Shaba S.Z., Tsado E.K.: Principal component analysis of morphological traits in thirty-nine accessions of rice (Oryza sativa L.) grown in a rainfed lowland ecology of Nigeria. - J. Plant Breed. Crop Sci. 4: 120-126, 2013.

Genty B., Briantais J.M., Baker N.R.: The relationship between the quantum yield of the photosynthetic electron transport and quenching of chlorophyll fluorescence. - Biochim. Biophys. Acta 990: 87-92, 1989.

Giuliani R., Koteyeva N., Voznesenskaya E. et al.: Coordination of leaf photosynthesis, transpiration and structural traits in rice and wild relatives (genus Oryza). - Plant Physiol. 162: 1632-1651, 2013.

Gu J., Yin X., Stomph T.J. et al.: Physiological basis of genetic variation in leaf photosynthesis among rice (Oryza sativa L.) introgression lines under drought and well-watered conditions. - J. Exp. Bot. 63: 5137- 5153, 2012.

Guru T., Padma V., Reddy D.V.V. et al.: Natural variation of top three leaf traits and their association with grain yield in rice hybrids. - Indian J. Plant Physi. 22: 41-146, 2017.

Hamaoka N., Yasui H., Yamagata Y. et al.: A hairy-leaf gene, BLANKET LEAF, of wild Oryza nivara increases photosynthetic water use efficiency in rice. - Rice 10: 20, 2017.

Haritha G., Swamy B.P.M., Naik M.L. et al.: Yield traits and associated marker segregation in elite introgression lines derived from $O$. sativa $\times$ O. nivara. - Rice Sci. 25: 19-31, 2018.

Haritha G., Vishnukiran T., Yugandhar P. et al.: Introgressions from Oryza rufipogon increase photosynthetic efficiency of KMR3 rice lines. - Rice Sci. 24: 85-96, 2017.

Harley P.C., Loreto F., Marco G.D., Sharkey T.D.: Theoretical considerations when estimating the mesophyll conductance to $\mathrm{CO}_{2}$ flux by analysis of the response of photosynthesis to $\mathrm{CO}_{2}$. - Plant Physiol. 98: 1429-1436, 1992.

Hu S.P., Zhou Y., Zhang L.et al.: Correlation and QTL analyses of total chlorophyll content and photosynthetic rate of rice (Oryza sativa L.) under water stress and well-watered conditions. - J. Integr. Plant Biol. 51: 879 - 888, 2009.

Hura T., Hura K, Grzesiak M.T.: The usefulness of chlorophyll fluorescence parameters in harvest prediction in 10 genotypes of winter triticale under optimal growth conditions. - Plant Biosyst. 143: 496-503, 2009.

IRRI.: STAR (Statistical Tool for Agricultural Research). Biometric and breeding informatics. Available online from: http://bbi.irri.org/products, 2013.

Ishikawa R., Watabe T., Nishioka R. et al.: Identification of quantitative trait loci controlling floral morphology of rice using a backcross population between common cultivated rice, Oryza sativa and Asian wild rice, O. rufipogon. - Am. J. Plant Sci. 8: 734-744, 2017.

Kaladhar K., Swamy B.P.M., Babu A.P. et al.: Mapping quantitative trait loci for yield traits in $\mathrm{BC}_{2} \mathrm{~F}_{2}$ population derived from Swarna x O. nivara cross. - Rice Genet. Newsl. 24: 3436, 2008.

Kaur R., Chakraborty A., Bhunia R.K. et al.: Wsils promoter from wild rice genotype, Oryza nivara, shows enhanced expression under soil water stress in contrast to elite cultivar, IR20. - J. Plant Biochem. Biot. 26: 14-26, 2017.

Kiran, T.V., Rao, Y.V., Subrahmanyam, D. et al.: Variation in leaf photosynthetic characteristics in wild rice species. Photosynthetica 51: 350-358, 2013.

Kondamudi R., Swamy K.N., Rao Y.V. et al.: Gas exchange, carbon balance and stomatal traits in wild and cultivated rice (Oryza sativa L.) genotypes. - Acta Physiol. Plant. 38: 160, 2016.

Kosambi D.D.: The estimation of map distances from recombination values. - Ann. Eugen. 12: 172-175, 1944.

Kumar A., Guha A., Bimolata W. et al.: Leaf gas exchange physiology in rice genotypes infected with bacterial blight: An attempt to link photosynthesis with disease severity and rice yield. - Aust. J. Crop Sci. 7: 32-39, 2013.

Kumari S.: Yield response of uniculm wheat (Triticum aestivum L.) to early and late application of nitrogen: flag leaf development and senescence. - J. Agr. Sci. 3: 170-182, 2011.

Lander E.S., Botstein D.: Mapping mendelian factors underlying quantitative traits using RFLP linkage maps. - Genetics 121: 185-199, 1989. 
Laza R., Peng S., Akita S. et al.: Effect of panicle size on grain yield of IRRI-released Indica rice cultivars in the wet season. - Plant Prod. Sci. 7: 27-276, 2004.

Lichtenthaler H.K., Wellburn A.R.: Determinations of total carotenoids and chlorophylls $a$ and $b$ of leaf extracts in different solvents. - Biochem. Soc. T. 11: 591-592, 1983.

Lincoln S.E., Daly M.J., Lander E.S.: Constructing genetic linkage maps with MAPMAKER/EXP 3.0. Pp. 97. Whitehead Institute for Biomedical Research, Cambridge 1993.

Liu G.L., Mei H.W., Yu X.Q. et al.: QTL analysis of panicle neck diameter, a trait highly correlated with panicle size, under well-watered and drought conditions in rice (Oryza sativa L.). - Plant Sci. 174: 71-77, 2008.

Long S.P., Marshall-Colon A., Zhu X.G.: Meeting the global food demand of the future by engineering crop photosynthesis and yield potential. - Cell 161: 56-66, 2015.

Luo X.J., Wu S., Tian, F. et al.: Identification heterotic loci associated with yield-related traits derived from Chinese common wild rice (Oryza rufipogon Griff.). - Plant Sci. 181: 14-22, 2011.

Ma X., Fu Y., Zhao X. et al.: Genomic structure analysis of a set of Oryza nivara introgression lines and identification of yield-associated QTLs using whole-genome resequencing. Sci. Rep. 6: 27425, 2016.

Ma L., Yang, C., Zeng D. et al.: Mapping QTLs for heading synchrony in a doubled haploid population of rice in two environments. - J. Genet. Genom. 36: 297-304, 2009.

Marri P.R., Sarla N., Reddy L.V. et al.: Identification and mapping of yield and yield related QTLs from an Indian accession of Oryza rufipogon. - BMC Genet. 6: 33, 2005.

Masumoto C., Ishii T., Kataoka S. et al.: Enhancement of rice leaf photosynthesis by crossing between cultivated rice, Oryza sativa and wild rice species, Oryza rufipogon. - Plant Prod. Sci. 7: 252-259, 2004.

Maxwell K., Johnson G.N.: Chlorophyll fluorescence - a practical guide. - J. Exp. Bot. 51: 659-668, 2000.

Mei H.W., Xu J.L., Li Z.K. et al.: QTLs influencing panicle size detected in two reciprocal introgressive line (IL) populations in rice (Oryza sativa L.). - Theor. Appl. Genet. 112: 648-656, 2006.

Murchie E.H., Hubbart S., Peng S., Horton P.: Acclimation of photosynthesis to high irradiance in rice: gene expression and interactions with leaf development. - J. Exp. Bot. 56: 449460, 2005.

Nachimuthu V.V., Robin S., Sudhakar D. et al.: Evaluation of rice genetic diversity and variability in a population panel by principal component analysis. - Indian J. Sci. Technol. 7: 1555-1562, 2014.

Niinemets U.: Is there a species spectrum within the world-wide leaf economics spectrum? Major variations in leaf functional traits in the Mediterranean sclerophyll Quercus ilex. - New Phytol. 205: 79-96, 2015.

Ono K., Maruyama A., Kuwagata T. et al.: Canopy-scale relationships between stomatal conductance and photosynthesis in irrigated rice. - Glob. Change Biol. 19: 22092220, 2013.

Quan R., Wang J., Hui J. et al.: Improvement of salt tolerance using wild rice genes. - Front Plant Sci. 8: 2269, 2018.

Prasanth V.V., Babu M.S., Basava R.K. et al.: Trait and marker associations in Oryza nivara and O. rufipogon derived rice lines under two different heat stress conditions. - Front. Plant Sci. 8: 1819, 2017.

Rahman M.A., Haque M.E., Sikdar B. et al.: Correlation analysis of flag leaf with yield in several rice cultivars. - J. Life Earth Sci. 8: 49-54, 2013.

$\mathrm{R}$ core team.: R: A language and environment for statistical computing. - R Foundation for Statistical Computing, Vienna, Austria. http://www.R-project.org/, 2012.

Richards R.A.: Selectable traits to increase crop photosynthesis and yield of grain crops. - J. Exp. Bot. 51: 447- 458, 2000.

Rogers S.O., Bendich A.J.: Extraction of DNA from plant tissue. - In: Gelvin S.B., Schilperoort R.A. (ed.): Plant Biology Manual. Pp. 1-10. Kluwer Academic Publ, Boston 1988.

Sabar M., Bibi T., Farooq H.U. et al.: Molecular screening of rice (Oryza sativa L.) germplasm for Xa4, Xa5 and Xa21 bacterial leaf blight (BLB) resistant genes using linked marker approach. - Afr. J. Biotechnol. 15: 2317-2324, 2016.

Sarao P.S., Sahi G.K., Neelam K. et al.: Donors for resistance to brown planthopper Nilaparvata lugens (Stål) from wild rice species. - Rice Sci. 23: 219-224, 2016.

Sellamuthu R., Ranganathan C., Serraj R.: Mapping QTLs for reproductive-stage drought resistance traits using an advanced backcross population in upland rice. - Crop Sci. 55: 15241536, 2015.

Sexton, T.M.: In vivo Rubisco kinetics in rice. - Available online at https://cas.wsu.edu/ask/wp-content/uploads/sites/458/2013/ 05/Thomas-Sexton-Research.pdf, 2013.

Shen Y.G.: Photosynthesis and Matter Production. Pp. 31-32. China Agriculture Publishing Company, Beijing 1980.

Silva M.D.A., Jifon J.L., Santos C.M.D. et al.: Photosynthetic capacity and water use efficiency in sugarcane genotypes subject to water deficit during early growth phase. - Braz. Arch. Biol. Technol. 56: 735-748, 2013.

Swamy B.P.M., Kaladhar K., Ramesha M.S. et al.: Molecular mapping of QTLs for yield and related traits in Oryza sativa cv Swarna x O. nivara (IRGC81848) backcross population. Rice Sci. 18: 178-186, 2011.

Swamy B.P.M., Kaladhar K., Reddy G.A. et al.: Mapping and introgression of QTL for yield and related traits in two backcross populations derived from Oryza sativa cv. Swarna and two accessions of $O$. nivara. - J. Genet. 93: 643-654, 2014.

Swamy B.P.M., Kaladhar, K., Shobharani N. et al.: QTL analysis for grain quality traits in $2 \mathrm{BC}_{2} \mathrm{~F}_{2}$ populations derived from crosses between Oryza sativa cv Swarna and 2 accessions of O. nivara. - J. Hered. 103: 442-452, 2012.

Takai T., Kondo M., Yano M. et al.: A quantitative trait locus for chlorophyll content and its association with leaf photosynthesis in rice. - Rice 3: 172-180, 2010.

Wang S., Basten C.J., Zeng Z.B.: Windows QTL Cartographer 2.5. Pp. 189. Department of Statistics, North Carolina State University, Raleigh 2011.

Wang S., Wu K., Yuan Q. et al.: Control of grain size, shape and quality by OsSPL16 in rice. - Nature Genet. 44: 950-954, 2012.

Xie X.J., Shen S.H., Li Y.X. et al.: Effect of photosynthetic characteristic and dry matter accumulation of rice under high temperature at heading stage. - Afr. J. Agric. Res. 6: 19311940, 2011.

Xing Y., Tan Y., Hua J.P. et al.: Characterization of the main effects, epistatic effects and their environmental interactions of QTLs on the genetic basis of yield traits in rice. - Theor. Appl. Genet.105: 248-257, 2002.

Xiong D., Flexas J., Yu T. et al.: Leaf anatomy mediates coordination of leaf hydraulic conductance and mesophyll conductance to $\mathrm{CO}_{2}$ in Oryza. - New Phytol. 213: 572-583, 2017.

Xu D.Q., Shen Y.G.: Progress on Physiology of Crop High Production and High Efficiency. Pp. 17-23. Sci. Publ. Company, Beijing 1994.

Xu F., Bao J., He Q. et al.: Genome-wide association study of eating and cooking qualities in different subpopulations of 
rice (Oryza sativa L.). - BMC Genomics 17: 663, 2016.

Xu J.L., Lafitte H.R., Gao Y.M. et al.: QTLs for drought escape and tolerance identified in a set of random introgression lines of rice. - Theor Appl Genet. 111: 1642-1650, 2005.

Xu J.L., Yu S.B., Luo L.J. et al.: Molecular dissections of the primary sink size and its related traits in rice. - Plant Breed. 123: 43-50, 2004.

$\mathrm{Xu}$ Z., Zhou G.: Responses of leaf stomatal density to water status and its relationship with photosynthesis in a grass. $-\mathrm{J}$. Exp. Bot. 59: 3317-3325, 2008.

Yeh S.Y., Chen H.W., Ng C.Y. et al.: Down-regulation of cytokinin oxidase 2 expression increases tiller number and improves rice yield. - Rice 8: 36, 2015.

Zhao M., Ding Z., Lafitte R. et al.: Photosynthetic characteristics in Oryza species. - Photosynthetica 48: 234-240, 2010.

Zhao M., Lafitte H.R., Sacks E. et al.: Perennial O. sativa x $O$. rufipogon interspecific hybrids:I. Photosynthetic characte- ristics and their inheritance. - Field Crops Res. 106: 203-213, 2008.

Zhao X., Li Y., Zheng M. et al.: Comparative analysis of growth and photosynthetic characteristics of (Populus simonii $\times P$. nigra $) \times(P$. nigra $\times P$. simonii $)$ hybrid clones of different ploidides. - PLoS ONE 10: e0119259, 2015.

Zhou S., Zhu M., Wang F. et al.: Mapping of QTLs for yield and its components in a rice recombinant inbred line population.Pak. J. Bot. 45: 83-189, 2013.

Zou G.H., Mei H.W., Liu H.Y. et al.:Grain yield responses to moisture regimes in a rice population: association among traits and genetic markers. - Theor. Appl. Genet. 112: 106113, 2005.

Zou J.H., Pan X.B., Chen Z.X. et al.: Mapping quantitative trait loci controlling sheath blight resistance in two rice cultivars (Oryza sativa L.). - Theor. Appl. Genet. 101: 569-573, 2000.

(C) The authors. This is an open access article distributed under the terms of the Creative Commons BY-NC-ND Licence. 